\title{
Ectopic FVIII expression and misfolding in hepatocytes as a potential cause of human hepatocellular carcinoma
}

Audrey Kapelanski-Lamoureux ${ }^{2^{*}}$, Zhouji Chen ${ }^{1^{*}}$, Zu-Hua Gao ${ }^{3,4}$, Ruishu Deng ${ }^{1}$, Anthoula Lazaris $^{4}$, Cynthia Lebeaupin ${ }^{1}$, Lisa Giles ${ }^{5}$, Jyoti Malhotra ${ }^{6}$, Jing Yong ${ }^{1}$, Chenhui Zou , Ype P. de Jong ${ }^{8}$, Peter Metrakos ${ }^{7}$, Roland W. Herzog ${ }^{10}$, Randal J Kaufman ${ }^{1,9,}$

1 Degenerative Diseases Program, SBP Medical Discovery Institute, La Jolla, United States

2 Department of Anatomy and Cell Biology, McGill University, Cancer Research Program, Research Institute of the McGill University Health Centre, Montreal, Quebec, Canada

3 Department of Pathology and Oncology, McGill University Health Centre, Montreal, Quebec, Canada

${ }^{4}$ Cancer Research Program, Research Institute of the McGill University Health Centre, Montreal, Quebec, Canada

5 Not affiliated with any institution

6 Sarepta Therapeutics, Boston MA, United States

7 Department of Surgery, McGill University; Cancer Research Program, Research Institute of the McGill University Health Centre, Montreal, Quebec, Canada

8 Division of Gastroenterology and Hepatology, Weill Cornell Medicine, New York, NY, United States

9 Department of Pharmacology, University of California, San Diego, La Jolla, United States

10 Herman B Wells Center for Pediatric Research, Indiana University, Indianapolis, IN, United States

* These authors contributed equally to this work.

*: Corresponding Author:

Randal J. Kaufman: rkaufman@sbpdiscovery.org 


\begin{abstract}
Clotting Factor VIII (FVIII) is the protein that is deficient in the X-linked bleeding disorder hemophilia A (HA). While HA therapy traditionally involves repeated infusions of FVIII protein concentrate, hepatic gene therapy is currently being tested in multiple clinical trials for sustained correction through expression in hepatocytes. FVIII is a $330 \mathrm{kDa}$ multi-domain glycoprotein. The B domain is dispensable, and B domain-deleted (BDD) FVIII is used clinically in protein replacement and in gene therapy. Previously, we observed that in vivo transfection with BDD-FVIII DNA vector resulted in FVIII misfolding and endoplasmic reticulum (ER) stress in murine livers. In other work, we demonstrated that mice exposed to transient ER stress and then fed a high fat diet (HFD) for 9 months developed hepatocellular carcinoma (HCC). Therefore, we deduced that ectopic expression of FVIII in murine hepatocytes followed by HFD feeding may also cause HCC. We find that, while BDD aggregates in the ER and induces hepatocyte apoptosis, the N6 variant is more efficiently folded and secreted and causes less hepatocyte apoptosis. We directed transient expression of BDD or N6 from a DNA vector in hepatocytes of 6-week-old mice. One week later, at a point when FVIII expression is extinguished, mice were fed 60\% HFD for 65 weeks. Remarkably, $100 \%$ of mice that received BDD developed liver tumors after 65 weeks, while only $58 \%$ of mice that received N6 (and none of the control mice that received empty vector) developed liver tumors. Of the mice injected with BDD vector DNA, 33\% developed carcinomas and 67\% developed adenomas. These findings raise attention regarding the safety of ectopic expression of FVIII in hepatocytes during FVIII gene therapy.
\end{abstract}




\section{Introduction}

Hemophilia A (HA) is an X chromosome-linked bleeding disorder affecting 24.6 per 100,000 males at birth that results from the deficiency of clotting factor VIII (FVIII) (1). Protein replacement therapy with recombinant FVIII has significantly reduced morbidity and mortality associated with HA, although concerns remain. First, inhibitory anti-FVIII antibodies develop in a significant number of patients (2). Second, recombinant FVIII protein bears a high cost with limited availability due to low and variable production from mammalian host cells, primarily Chinese Hamster Ovary $(\mathrm{CHO})$ or baby hamster kidney (BHK) cells (3). FVIII secretion from mammalian cells is inefficient, partly due to FVIII protein misfolding, aggregation and retention in the endoplasmic reticulum (ER) (4). Misfolded FVIII activates a cellular adaptive program called the unfolded protein response (UPR) to resolve defective protein folding. However, upon chronic protein misfolding in the ER the UPR shifts to an apoptotic program.

FVIII is a $330 \mathrm{kDa}$ glycoprotein comprised of three domains (A1-A2-B-A3-C1-C2) (1). Liver sinusoidal endothelial cells are the major site for FVIII synthesis (2). The amino acid sequences in the $A$ and $C$ domains are highly conserved between species, whereas amino acid sequences within the large $B$ domain, encoded by a single $3 \mathrm{~kb}$ exon, are not conserved. In addition, the B domain bears an unusually large number (18) of $\mathrm{N}$-linked oligosaccharides that are also observed in FVIII B domains from different species, as well as the homologous factor V B domain. The B domain is dispensable for the secretion of FVIII and its functional FVIII activity $(3,4)$. In fact, B domain-deleted (BDD) FVIII (A1-A2-A3-C1-C2) (Fig. 1), described herein, is very similar to the SQ-BDD/FVIII-SQ (Refacto, Pfizer)(5), which is an effective protein replacement therapy for HA patients $(6,7)$. The only difference between BDD and SQ-BDD is that SQ-BDD contains an extra 14 amino acid linker (SFSQNPPVLKRHQR) at the junction between A2 and A3 domains of BDD $(8,9)$. BDD and SQ-BDD are used interchangeably in the literature (8) and exhibit similar misfolding problems in culture systems. Subsequent codon optimization improved SQ-BDD production leading to its use in the ongoing HA gene therapy clinical studies (8-12). SQ-BDD is being used for AAV FVIII gene delivery in HA because of the limited packaging constraints of the AAV genome, which is $<5 \mathrm{~kb}(11)$. However, BDD exhibits similar misfolding as intact wildtype human FVIII and activates the UPR leading to hepatocyte death upon in vivo DNA vector delivery to hepatocytes in mice (13). In contrast to BDD, we described a partial B domain deletion molecule, herein (N6), that retains an additional 226 aa with $6 \mathrm{~N}$-linked glycosylation sites from the $\mathrm{N}$-terminal portion of the $\mathrm{B}$ domain, and is secreted $\sim-5-10$-fold more efficiently than full-length FVIII or BDD (13), presumably because the $6 \mathrm{~N}$-glycans engage intracellular lectin 
chaperone machinery that were demonstrated to enhance FVIII trafficking from the ER to the Golgi compartment (14-19). For a detailed description of different BDD molecules, see Fig. 1. The key difference between structures of BDD and N6 is that the B domain of wtFVIII is completely deleted in $\operatorname{BDD}(\Delta 741-1647)$ whereas $\mathrm{N} 6$ retains a 226 amino acid $\mathrm{B}$ domain segment (aa's 741-966) that contains $6 \mathrm{~N}$-linked glycosylation sites (20). N6 is secreted more efficiently and causes less toxic cellular responses than BDD (Fig. 1).

Detailed studies of full-length human FVIII expression in mammalian cells demonstrated that FVIII forms amyloid-like aggregates in the ER. Aggregate formation occurred when a threshold of FVIII expression was surpassed $(21,22)$. In addition, aggregation was increased upon glucose deprivation, and upon glucose repletion the FVIII aggregates dissolved and, remarkably, refolded to produce functional secreted FVIII. Finally, these studies demonstrated that an amino acid sequence motif in the A1 domain was necessary and sufficient to seed $\beta$-sheet polymerization in FVIII (21).

Presently, there are numerous ongoing adeno-associated-viral (AAV) gene therapy clinical studies to deliver codon-optimized BDD to hepatocytes in men with severe HA. Initial results appeared to be very successful, with correction of FVIII levels into the normal during the first year $(9,10)$. Substantial improvement in hemostasis was documented in a 5-yr follow-up (23). Unfortunately, elevated liver enzyme levels were observed in the first year, and FVIII expression levels gradually declined to the lower end of the therapeutic range, starting in the second year (24-27). Although the cause for the decline in FVIII expression in the clinical setting is unknown, it is possible that FVIII misfolding and UPR activation impact hepatocyte function, health and/or survival. Therefore, there is an urgent need to understand mechanisms underlying inefficient FVIII secretion both for engineered bio-production, and importantly, for in vivo clinical HA gene therapy (24-26).

Liver cancer is a major health issue worldwide as it is the third most common cause of cancerrelated death and the most common primary liver cancer accounting for $90 \%$ of the cases (28). The incidence of hepatocellular carcinoma (HCC) has tripled since 1980 and is the most increasing cause of cancer mortality in the U.S (28). Whereas the 5-year survival rate for localized $\mathrm{HCC}$ is $32.6 \%$, it is $10.8 \%$ in regional disease and $2.4 \%$ in distant disease, underscoring the importance of early detection (29). HCC develops as a consequence of an underlying chronic liver disease. While the incidence of viral-related HCC is declining, HCC related to metabolic stress is on the rise, due to the global increase in obesity and the associated 
metabolic syndrome. As a result, nonalcoholic steatohepatitis (NASH) is the leading cause of liver transplants in developed countries and it is estimated to become the dominant HCC etiology. A quarter of the world's population suffers from non-alcoholic fatty liver disease (NAFLD) characterized by abnormal lipid accumulation in hepatocytes. A subset of NAFLD patients also develops NASH with inflammation, hepatocyte ballooning, Mallory Denk Bodies, cell death and fibrosis, leading to cirrhosis. HCC is associated with cirrhosis in up to $70 \%$ of cases (28). Both ER stress and activation of the UPR are documented in many different human diseases $(30,31)$, including NASH and HCC (32-34).

Previously, we demonstrated that protein misfolding in the ER of hepatocytes in mice can initiate the development of NASH and hepatocellular carcinoma (HCC) (35). This study used transgenic mice that express the plasminogen activator urokinase (UPA) under the control of the major urinary protein promoter (MUP). These (MUP-uPA) mice express uPA until 6 wks of age that is subsequently extinguished by $10 \mathrm{wks}$, presumably due to hepatocyte toxicity of misfolded uPA expression (35). At 10 wks of age the mice were fed a high fat diet (60\% calories from high fat) (HFD) for 10 mon. Although transgenic and wild-type mice developed fatty liver disease, only the MUP-uPA transgenic mice developed features of NASH. After 10 mon all transgenic mice developed HCC that was not observed in wild-type mice that do not express UPA. Thus, it appears transient (up to 10 wks of age) expression of a misfolded protein in the ER that activates the UPR followed by a HFD can initiate HCC development. Based on these findings we tested whether transient expression of FVIII that is prone to misfolding also exhibits similar HCC formation in mice.

Here we studied the long-term outcome of transient expression of BDD, which aggregates in the cell and activates the UPR, and the N6 derivative that displays reduced aggregation and UPR activation. We delivered BDD and N6 expression vectors by tail vein hydrodynamic DNA injection, for which FVIII expression was extinguished after 5 days. One wk after vector DNA injection, mice were fed a high fat diet for 65 weeks at which we observed greater tumor formation in BDD injected mice than N6 injected mice. Our findings demonstrate the potential risk concerning the ectopic expression of FVIII in the hepatocytes.

\section{Results}

\section{FVIII forms aggregates that resolve as early as $1 \mathrm{hr}$ following energy repletion.}

Stable expression of BDD and N6 FVIII in CHO cells, demonstrated that N6 expression was tolerated at an $\sim 10$-fold greater level than BDD. We previously characterized full-length FVIII 
aggregation by filtration of cell lysates through nitrocellulose (NC) membranes, which retain all cell proteins, or cellulose acetate (CA) membranes, which only retain proteins that have $\beta$-sheet aggregate structures (21). Lysates filtered onto membranes were probed with FVIII or $\beta$-actin antibodies. Filtration through NC membranes demonstrated that intracellular levels of BDD were 5-10-fold greater than N6, proportional to the higher level of N6 FVIII secretion. Filtration through CA membranes demonstrated significant aggregation of BDD and $\sim 3$-fold less aggregation for N6, although N6 was expressed at a 5-10-fold greater level than BDD (Fig. 2A). Following energy depletion by treatment with 2-deoxyglucose (2-DG) and sodium azide $\left(\mathrm{NaN}_{3}\right)$ to inhibit glycolysis and oxidative phosphorylation, respectively, FVIII aggregates accumulated in $\mathrm{CHO}$ cells that stably express wtFVIII $\left(\sim 500 \mathrm{mU} / \mathrm{ml} / 10^{6}\right.$ cells/day, not shown) (21), BDD ( 1U/ml/106 cells day) and N6 ( 10U/ml/106 cells day). We previously demonstrated that 2-DG, and not $\mathrm{NaN}_{3}$, was sufficient to induce wild-type FVIII aggregation (21). After removal of 2-DG and glucose replenishment, BDD and N6 aggregates began to disappear at $1 \mathrm{hr}$, in a manner that did not require de novo protein synthesis, as the addition of the protein synthesis elongation inhibitor cycloheximide (CHX) did not alter aggregate dissolution (Fig. 2A). Note that oxidative phosphorylation inhibition by $\mathrm{NaN}_{3}$ is irreversible.

We performed $\left[{ }^{35} \mathrm{~S}\right]$-met/cys - pulse-chase labeling that confirm glucose deprivation retained BDD and N6 within the cell, and that upon glucose repletion, intracellular aggregated FVIII dissolved and was efficiently secreted into the medium (Fig. 2B). Analysis of FVIII activity in the media treated under the same conditions as the pulse-chase assay demonstrated that the secreted FVIII is functional (Fig. 2B, aPTT assay). Increasing amounts of functional FVIII appeared in the media as early as $1 \mathrm{hr}$ following glucose repletion for BDD and at $2 \mathrm{hr}$ for N6, which both correlated with the disappearance of intracellular aggregated FVIII. Although the amount of previously metabolically labeled FVIII secreted following glucose repletion was not affected by the addition of $\mathrm{CHX}$ to the repletion media, $\mathrm{CHX}$ treatment reduced secreted FVIII activity to $30-60 \%$, presumably due to inhibition of new FVIII synthesis. The sum of these results (Figs. 2A-B) indicates that a major percent of both BDD and N6 metastable aggregates can resolve to produce folded, functional and secreted FVIII.

\section{Ectopic FVIII expression via hydrodynamic tail vein injection causes protein aggregation in murine livers.}

Hydrodynamic tail vein injection is an efficient method to express exogenous genes in hepatocytes $(20,36)$. Using this technique, we confirmed that expression of exogenous FVIII in hepatocytes of mice injected with BDD or N6 vector DNA induced the UPR, although the stress 
response to N6 expression was significantly attenuated (13). We next tested whether the stress response from FVIII gene delivery to hepatocytes is associated with protein aggregation in vivo by measuring thioflavin-S (Thio-S) staining. The livers of BDD vector-injected mice showed significantly more Thio-S positivity than N6 vector-injected mice, evidenced by colocalization of Thioflavin-S staining with FVIII immunostaining (Fig. 3).

\section{BDD is misfolded in murine hepatocytes in vivo.}

Misfolded proteins bind the ER chaperone BiP/GRP78 while well-folded proteins do not $(37,38)$. Therefore, protein interaction with BiP can be used as a surrogate to measure ER protein misfolding. However, there are no available antibodies that can quantitatively coimmunoprecipitate (IP) BiP-client protein complexes. Hence, we created a genetically modified mice with a 3x FLAG tag in the endogenous BiP/GRP78/Hspa5 locus (BiP-Flag mice) to allow for quantitative isolation of BiP-client protein complexes using anti-FLAG magnetic beads without altering BiP function (Figs. 4A-B; $(39,40)$. Importantly, the hepatocyte-specific expression of BiP-Flag is at the same level as endogenous and is regulated identically to the endogenous Hspa5 locus. To gain further insight into the folding status of BDD and N6 ectopically expressed in murine hepatocytes, we expressed BDD and N6 in livers of BiP-Flag homozygous ( $\left.\mathrm{BiP}-\mathrm{Flag}^{+/}\right)$mice by hydrodynamic tail vein injection of vector DNA and analyzed the interactions between BiP-FLAG and BDD or N6 through anti-FLAG co-IP of BDD and N6 (Fig. 4C). In agreement with our previous observations (13), intracellular hepatocyte BDD levels in BDD vector-injected mice were significantly higher than those in the N6 vector-injected mice (Fig. 4C, lanes $21 \& 22$ vs lanes $23 \& 24$ ), consistent with the greater retention of BDD in the ER. Importantly, anti-FLAG IP pulled down a significant portion of BDD from the livers of BDD vector-injected BiP-Flag ${ }^{+/}$mice (Fig. 4C, lanes 13-14). N6 was pulled down at a $70 \%$ lesser level (Fig. 4C, lanes 13 \&14 vs 17 \&18). These results support the notionthat BDD exhibits greater misfolding than $\mathrm{N} 6$ in hepatocytes of murine livers, which may account for the different degrees of UPR induction (13).

\section{Lentiviral transduction of BDD into human primary hepatocytes activates the UPR.}

We then used mouse-passaged human primary hepatocytes $(\mathrm{PHH})(41)$ to investigate the cellular response to ectopic BDD expression. $\mathrm{PHH}$ were transduced in vitro with increasing amounts of a lentiviral vector that expresses a codon-optimized form of SQ-BDD (8) that is used in HA gene therapy trials $(9,10,12)$. Consistent with our findings on BDD expression in $\mathrm{CHO}$ cells and livers of mice injected with BDD expression vector DNA (13), Western blot analysis demonstrated SQBDD expression induced UPR markers BiP, elF2 $\alpha$ phosphorylation and $\mathrm{CHOP}$, despite its weak 
signal, at 10 days after infection (Fig. 5). Interestingly, the expression of two UPR-induced genes in the liver, hepcidin (42) and cysteine-rich with EGF like domains 2 (CRELD2), an oncogene (43, 44), was increased in BDD-expressing $\mathrm{PHH}$. Thus, for the first time the results show ectopic BDD expression induces ER stress in human hepatocytes.

\section{HCC development correlates with the degree of ER protein misfolding.}

Based on previous findings that suggest protein misfolding in the ER can initiate NASH and HCC development (35), we tested whether two different FVIII variants that misfold to different degrees can initiate pathways of HCC development. Mice were subjected to hydrodynamic tail vein DNA injection of empty vector, BDD or N6 in C57BL/6J mice as described (13). After 24h, expression of N6 FVIII detected in the plasma was significantly higher than BDD (Fig. 6A), consistent with prior results (13). After $1 \mathrm{wk}$, when FVIII expression was not detectable, which is typical of tail vein DNA delivery to hepatocytes, mice were fed a $60 \%$ high fat diet for $65 \mathrm{wks}$. Then, mice were analyzed for liver surface tumors which demonstrated no tumors, adenomas of adenocarcinomas, in mice that received empty vector DNA. In contrast, all mice that received BDD expression vector developed tumors (Fig. 6B). Reduced tumor formation (58\%) was observed in mice that received the N6 vector (Fig. 6B). These surprising findings encouraged us to deeply characterize the adenomas and carcinomas in these mice. A detailed summary of this histopathological analysis is provided in Supplementary Tables I and 2.

Using strict diagnostic standards by $H \& E$ and reticulin staining, slides were evaluated independently by three clinical pathologists, two from the Mayo Clinic (MN, USA) and one from McGill University Health Center Department of Pathology and Oncology (Quebec, Canada). Histological evaluation showed the presence of steatosis in the liver parenchyma, most likely induced by the HFD. Immunohistochemistry staining of CD34, glutamine synthetase, $\beta$-catenin, glypican 3 and CD44 were also performed to assist the diagnosis. Although, no tumors were detected in any of the 8 mice injected with empty vector, we observed that $58 \%(7 / 12)$ of mice given N6 vector developed liver tumors; in contrast to $100 \%(10 / 10)$ of mice given BDD vector (Fig. 6B, p<0.02, Chi-square test). The findings suggest a higher penetrance of tumors in the presence of BDD misfolded protein. Histopathological assessment of the BDD injected mice confirmed that 6 of the 10 lesions were adenomas and 4 carcinomas (Fig. 6B) and the N6 vector DNA-injected mice developed 4 adenomas and 3 carcinomas (Supplemental Fig. 1B). The adenomas were overall negative for CD34 whereas the carcinomas displayed a patchy strong CD34-positive staining (Fig. 6C; Supplemental Fig. 2), further confirming the malignancy (45, 46). Most carcinomas had positive glutamine synthetase (GS) staining, indicative of an early- 
stage HCC (47). However, a few well-differentiated HCCs and an early evolving HCC, arising from adenomas were GS negative. As expected, $\beta$-catenin immunostaining showed identical results as GS as they are both frequently overexpressed in early HCC (47). Finally, the adenomas in the BDD cohort were positive for CD44, with the sinusoidal lymphocytes staining, however the adenomas in the N6 were negative. Based on the histopathological assessment, the distribution of adenomas and carcinomas are similar in both groups (Fig. 6C; Supplemental Fig. 1C). However, significantly, all BDD mice developed more tumors and thus a more aggressive phenotype.

\section{Partial deletion of the FVIII B domain reduces BiP protein levels in carcinomas.}

Tumor cells among the BDD carcinomas had significantly higher $(p=0.04)$ BiP protein levels compared to N6 carcinomas (Figs. 7 and 8). Similarly, we observed the same trend comparing distal normal liver BiP signal positivity $(p=0.01)$ (Fig. 7A). Tumor cells among the N6 adenomas had no significant differences in BiP protein levels compared to BDD adenomas (Fig. 7A). However, two of the BDD adenomas had high BiP levels, which skews the positivity to show no significant difference. One of the cases was an inflammatory subtype adenoma and the other a mild steatosis. The BDD adenomas compared to BDD carcinomas showed a significant decrease in BiP protein levels $(p=0.02)$ central of the tumor and N6 adenomas compared to N6 carcinomas showed no significant differences for all regions of interest (Supplemental Fig. 3). Therefore, it appears that the transient expression of BDD or N6 may display memory after 65 wks of HFD upon analysis of those tumors. It is possible epigenetic modifications may persist during initiation and progression of $\mathrm{HCC}$, a subject that requires further investigation. It is notable that $\mathrm{BiP}$ expression reduces apoptosis, which may account for the higher levels in HCC.

\section{Discussion}

Hepatic gene transfer of codon-optimized SQ-BDD-FVIII using AAV vectors has emerged as a promising therapeutic approach for HA. However, this gene therapy approach has encountered two major hurdles: 1) A requirement for very high vector doses to drive FVIII expression in hepatocytes; and 2) Declining therapeutic transgene expression over time accompanied with signs of liver damage, both of which may be directly linked to the fact that FVIII is retained and prone to misfolding in the ER. The decline in FVIII expression is a major issue that needs to be solved prior to FDA approval of this novel approach to treat HA. Recent HA gene therapy clinical studies suggest the expression is not durable, which is a major factor in considering gene therapy for $\mathrm{HA}$, as it is safely and effectively treated by prophylaxis with recombinant FVIII as well as FVIII- 
bypassing molecules such as a bispecific antibody (27). Thus, the safety and efficacy bars are raised for the evaluation of HA gene therapy regimens. The high significance of this problem has been highlighted in recent editorials $(24,48,49)$. Here, we demonstrate the tumorigenic potential for cellular stress resulting from even transient hyper expression of FVIII in hepatocytes. Encouragingly, we find that better secreted FVIII variants can be developed that reduce this risk. While there are differences in the biology of human and murine HCC and AAV gene transfer differs from plasmid vectors, these outcomes warrant more extensive investigations on the potential of current gene therapy approaches to cause tumor formation in patients with HA.

Since it is likely that nearly all approaches to cell/gene therapy for HA will involve overexpression or ectopic expression of FVIII, understanding the biosynthetic pathway, host factors and cellular responses to misfolded FVIII is critical. Significantly, we demonstrated that increased FVIII synthesis does not translate to increased FVIII secretion (21). We propose that simply increasing FVIII expression in transduced cells may not be sufficient to overcome potential unwanted offtarget and toxic responses. This view is further supported by a recent publication, showing that the overexpression of BDD-FVIII in murine hepatocytes from an AAV vector induces UPR (50), which may be avoided by achieving therapy through limited expression in a high percentage of hepatocytes.

We, and others, have identified new aspects of hepatocyte function that are impacted by protein misfolding in the ER that include: 1) Altered lipid metabolism and reduced export; 2) Alterations in insulin responses and control of glucose metabolism; 3) Activation of the systemic innate inflammatory response; 4) Activation of the ER UPR which inhibits lipid mobilization and fatty acid oxidation producing steatosis, and 5) Activation of cell death pathways. More significantly, we here demonstrate that transient expression of BDD or N6 FVIII is sufficient to initiate pathways of HCC development, when subsequently challenged by a high fat diet. Our findings support the notion that protein misfolding in the ER is sufficient to induce hepatocarcinogenesis is very important, especially in the context of gene therapy. We propose that HCC develops in response to repeated rounds of hepatocyte death and proliferation in the cirrhotic liver. Compensatory proliferation might create a permissive environment for the genetic and epigenetic changes to result in oncogene activation and/or loss of function of tumor-suppressor genes $(30,51)$.

Our previous work identified an FVIII molecule, N6, that is more efficiently secreted and less prone to aggregation than present B-domain deletion molecules being tested for HA gene therapy (13, 20). In addition to the increased secretion efficiency of N6 compared to BDD, N6 elicits reduced 
cellular toxicity, as measured by UPR activation, apoptosis, inflammation (INF), steatosis, levels of reactive oxygen species (ROS), steatosis, protection by antioxidant BHA treatment and HCC (Fig. 1) $(13,20,52,53)$.

We tested whether expression of BDD or N6 truncated FVIII proteins that cause different degrees of protein misfolding and UPR activation can induce HCC upon subsequently feeding an HFD. In essence, is the degree of protein misfolding in the ER correlated with subsequent HCC development. N6 folds and is secreted more efficiently than BDD when expressed in hepatocytes. Thus, a higher level of N6 FVIII is tolerated by hepatocytes in vivo. This is consistent with analysis of expression of these two molecules in $\mathrm{CHO}$ cells (Fig. 2). Using our recently generated $B i P / G R P 78 / H s p a 5-k n o c k i n$ mice harboring a $3 X$ Flag tag in the C-terminus of BiP in the endogenous BiP/GRP78/Hspa5 locus (40) to assess the folding status of BDD accumulated in hepatocytes in vivo, we show that nearly half of intrahepatocellular BDD binds BiP (Figure 3), indicative of misfolding. This finding provides evidence that supports our hypothesis that compared to N6, ectopic expression of BDD induces a much higher level of misfolded FVIII in the liver, which can induce a series of cytotoxic responses, including activation of the UPR, and ultimately leading to initiation of HCC development. This BiP-Flag mouse model should be incorporated to evaluate the misfolding propensity of any BDD derivatives considered for gene therapy.

Our findings suggest that characterization of the folding efficiency, host response and safety in model organisms and non-human primates is essential to ensure safety over the lifetime of an individual. Unfortunately, HCC takes years to develop in humans. A case of HCC has occurred in a hemophilia B patient after hepatic AAV-mediated factor IX gene transfer (54). In this event, tumor formation was highly unlikely caused by gene therapy as it occurred early after gene transfer and the patient had multiple risk factors that pre-disposed to HCC formation. HCC formation has been observed in murine studies with AAV vectors using other transgenes and was attributed to insertional mutagenesis (although the bulk of AAV vector genomes persists episomally, integration does occur). Interestingly, HCC only developed upon neonatal gene transfer but not in mice transduced as adults unless they were fed a HFD leading to NAFLD (55), which was associated with increased inflammation and hepatocyte proliferation, consistent with our findings. Other studies on AAV gene delivery to the liver have not detected NASH or HCC. This is expected because all murine models of $\mathrm{NASH}$ and $\mathrm{HCC}$ progression require a hypercaloric diet, presumably to induce an inflammatory environment $(56,57)$. 
However, our new results show that high levels of FVIII gene expression by itself, even if transient and very likely independent of insertional events, can induce HCC in the context of a high-fat diet. HCC has not been observed in animals treated with AAV-FVIII vectors. This may in part be due to limited follow-up in mice or relatively low levels of expression in dogs that were followed longer. Clonal expansion of canine hepatocytes has recently been shown $\sim 3$ years after AA-FVIII gene transfer, although this did not lead to tumors (58). Nevertheless, it must be considered that our studies do not reflect the course of liver disease in clinical studies, nor the therapeutic approach. For instance, we used DNA delivery in our mouse studies because we previously characterized detailed responses to BDD vs N6 (13). It is possible that in AAV gene transfer the amount of FVIII produced by hepatocytes does not typically reach a threshold required to set off the cascade of molecular events that promotes HCC. Long-term follow-up in patients who had high levels of expression will be required to answer this question.

Current eligibility criteria for enrollment in AAV-FVIII trials exclude subjects with advanced liver fibrosis, hepatitis B surface antigen, and hepatitis C RNA, among others. Since there are no apparent mutation characteristics that predict the potential for HCC development, genetic profiling as a criterion for entry into gene therapy is unlikely. Being the effective replacement/bypass therapies available, the criteria for entry into a clinical trial for AAV-FVIII gene therapy needs careful consideration. Our studies support the need for careful monitoring of liver function over the time course of gene therapy treatment. Moreover, we demonstrate a role of diet in particular when expressing a therapeutic protein in the liver that is prone to misfolding and ER stress. While AAV-FVIII gene transfer has not been found to cause the level of hepatocyte apoptosis and liver injury that may occur with DNA vectors, multiple studies have shown induction of ER stress markers in mice in response to AAV-FVIII $(50,59,60)$, and liver injury (albeit of unknown origin) occurred in patients treated with high-dose AAV-FVIII $(9,10)$ We have now directly shown that expression of SQ-BDD in primary human hepatocytes induced ER stress in a dose-dependent manner (Fig. 5). Together, our study provides experimental evidence demonstrating the need for rigorous scientific investigations towards the pathophysiological consequence upon AAV-mediated FVIII expression in the hepatocytes to improve the efficacy and safety of HA gene therapy. 


\section{Materials and Methods}

\section{Materials for cellular and molecular biology}

Anti-factor VIII heavy chain monoclonal antibody coupled to Sepharose CL-4B was obtained from Baxter/Baxalta Corp. FVIII-deficient and normal pooled human plasma were obtained from George King Biomedical (Overland Park, KS). Activated partial thromboplastin (automated aPTT reagent) and $\mathrm{CaCl}_{2}$ were purchased from General Diagnostics Organon Teknika (Durham, NC). Dulbecco modified Eagle medium (DMEM), glucose- free DMEM, alpha-modified essential medium (alpha-MEM), cysteine/methionine-free DMEM, and fetal bovine serum (FBS) were purchased from Gibco BRL. FVIII:C-EIA was purchased from Affinity Biologicals. Anti- $\beta$-actin antibody, 3-methyladenine, 2-deoxy-D- glucose, and sodium azide were obtained from Sigma Aldrich. Anti-FVIII antibody (GMA012) was obtained from Green Mountain. [ ${ }^{35}$ S]Methionine/Cysteine was obtained from MP Biologicals. Mouse and rabbit horseradish peroxidase conjugated secondary antibodies, Prolong Antifade Gold and Complete Protease Inhibitor Cocktail were obtained from Promega. Supersignal West Pico ECL was obtained from Thermo. Mouse FAB fragments, Dylight 549 conjugated anti-mouse fab fragments and TexasRed conjugated anti-mouse secondary were obtained from Jackson Immunoresearch.

\section{Mice}

Male C57BL/6J mice were purchased from Jackson Laboratory and maintained at the SanfordBurnham-Prebys Medical Discovery Institute animal facility. Mice were euthanized by $\mathrm{CO}_{2}$ inhalation for liver harvest. All animal protocols were reviewed and approved by the Institutional Animal Care and Use Committee at the SBP Medical Discovery Institute.

\section{Hydrodynamics-based delivery of plasmid DNA and HCC development}

The expression vectors for BDD and N6 were previously described (20). Six wk-old mice were used for these experiments. Hydrodynamic tail vein DNA injection was performed according to previous publications $(13,36)$. In summary, $100 \mu \mathrm{g}$ plasmid DNA was diluted in $2.5 \mathrm{ml}$ saline and injected into mice through the tail vein. One wk after the injection, mice were fed $60 \%$ HFD for 65 wks after which their livers were harvested for tumor evaluation.

\section{Glucose depletion and repletion}

For glucose depletion, cells were treated with ATP-depleting medium (glucose-free DMEM containing $20 \mathrm{mM}$ 2-deoxy-D-glucose and $10 \mathrm{mM}$ sodium azide) for $2 \mathrm{hr}$. To replete glucose, fresh media was replaced for the indicated time. Cycloheximide at a final concentration of 10 
$\mu \mathrm{g} / \mathrm{mL}$ was added to the repletion media where indicated.

\section{Factor VIII activity and antigen analysis}

FVIII activity was measured by a 1-stage aPTT clotting assay on an MLA Electra 750 fibrinometer (Medical Laboratory Automation, Pleasantville, NY) by reconsititution of human FVIII-deficient plasma. The FVIII plasma standard was FACT plasma (normal pooled plasma) from George King Biomedical. FVIII antigen was quantified by an anti- FVIII sandwich enzyme-linked immunosorbent assay (ELISA) method using the Affinity Biologicals FVIII:C-EIA commercial kit according to the manufacturers' instructions.

\section{Metabolic labeling}

Cells were subcultured $24 \mathrm{~h}$ prior to labeling in $60 \mathrm{~mm}$ dishes (approximately $10^{6} \mathrm{cells} / \mathrm{plate}$ ) and were $80 \%$ confluent at the time of labeling. Cells were washed twice in cys/met free DMEM and incubated in cys/met-free DMEM for $10 \mathrm{~min}$ prior to labeling. Cells were labeled in $0.5 \mathrm{ml}$ cys $/ \mathrm{met}$ free DMEM containing $100 \mu \mathrm{Ci} / \mathrm{mL}$ (BDD-FVIII and N6-FVIII) for $20 \mathrm{~min}$ and chased for indicated times with conditioned medium (either ATP-depleting medium or normal medium) containing excess unlabeled cysteine and methionine and $10 \mu \mathrm{g} / \mathrm{ml}$ aprotinin. For glucosedepletion/repletion conditions, depleting medium was removed after $2 \mathrm{~h}$ and replaced with normal medium containing excess unlabeled cysteine and methionine and aprotinin as above. At the end of the chase period, conditioned media was collected. Cells were rinsed three times in phosphate buffered saline (PBS) and harvested in $1 \mathrm{ml}$ lysis buffer [50 mM Tris- $\mathrm{HCl}, \mathrm{pH} 7.4$, $150 \mathrm{mM} \mathrm{NaCl}, 0.1 \%$ (v/v) Triton X-100, and 1\% (v/v) IGEPAL] containing Complete Protease Inhibitor Cocktail and $1 \mathrm{mM}$ phenylmethylsulfonyl fluoride. Lysates were incubated on ice 30 min, followed by centrifugation at $15,000 \times \mathrm{g}$ for $10 \mathrm{~min}$. Post-nuclear supernatant was then assayed for protein content using BCA assay (Bio-Rad). Equal amounts of protein and corresponding amounts of media were subjected to FVIII immunoprecipitation using anti-FVIII coupled Sepharose CL-4B beads at $4^{\circ} \mathrm{C}$ overnight. Immunoprecipitates were washed 4 times with lysis buffer and proteins were separated by SDS-PAGE polyacrylamide gel. Immunoprecipitated proteins were visualized by autoradiography and band intensities were quantified using ImageQuant normal media for the indicated time. Cycloheximide at a final concentration of $10 \mu \mathrm{g} / \mathrm{mL}$ was added to the repletion media where indicated.

\section{Interaction of BDD and N6 with BiP in vivo.}

The BiP-Flag mice were generated as described (40). Mice were fed a regular mouse chow diet. Induction of BiP-FLAG expression was initiated at the age of 6 wks by transduction with AAV8- 
TGB-Cre (40). AAV8-TGB-Cre-transduced wild type littermates were used as controls. At 6 wks after AAV8-TGB-Cre-transduction, the mice received pMT2 empty vector, BDD vector, or N6 vector through hydrodynamic tail vein injection (13) and were sacrificed to collect liver tissues 46 h post-vector DNA injection.

Liver samples were harvested in a lysis buffer [0.15 mM NaCl, 0.5\% Triton X-100, $20 \mathrm{mM} \mathrm{HEPES,}$ $\mathrm{pH} 7.4,1 \times$ Protease inhibitor cocktail (Fisher)]. The liver lysates were centrifuged at $10 \mathrm{~K} \times \mathrm{g}$ for $10 \mathrm{~min}$ and the resultant supernatants were used for anti-FLAG or anti-FVIII IP. For anti-FLAG $\mathrm{IP}, 150 \mu \mathrm{g}$ of lysates proteins in $400 \mu \mathrm{l}$ of lysis buffer was mixed with $15 \mu \mathrm{l}$ of M2 anti-FLAG magnetic beads (Sigma) and incubated with rotation at $4^{\circ} \mathrm{C}$ for $4 \mathrm{~h}$. At the end of this incubation, the anti-FLAG beads were washed $3 \mathrm{x}$ with ice-cold lysis buffer ( $1 \mathrm{ml}$ each). Direct anti-FVIII IP was performed in a similar manner except that $75 \mu \mathrm{g}$ of lysate protein and $25 \mu \mathrm{l}$ of anti-FVIIIcoupled agarose beads (21) were used in place of anti-FLAG beads. Proteins in the washed antiFLAG and anti-FVIII beads were eluted with SDS-PAGE loading buffer, separated by SDS-PAGE under reducing conditions and transferred onto Nitrocellulose membranes for Western blotting. $A$ mouse anti-human FVIII antibody (GAM012, Green Mountain) was used for BDD and N6 detection.

\section{Ex vivo experiment with mouse-passaged primary human hepatocytes}

Mouse-passed primary human hepatocytes (PHH) were prepared and cultured as described (41). They were transduced with a lentiviral vector expressing a codon-optimized form of SQBDD coding sequence (Lenti-BDD) (8) at the indicated doses 3 days after isolation and being cultured ex vivo and harvested for Western blot analysis 10 days after transduction.

Antibodies used were as follows: Rabbit anti-BiP, rabbit anti-phospho elF2 $\alpha$ and rabbit antielF2 $\alpha$ were from Cell Signaling Technology, (Danvers, MA). Mouse anti-human FVIII was from Green Mountain Antibodies (Burlington, VT); Mouse anti-CHOP was from Santa Cruz Biotechnology (Santa Cruz, CA); Rabbit anti-CRELD2 and mouse anti-hepcidin antibodies were from Proteintech (Rosemont, IL) and Novus Biologicals (Burlington, Vt), respectively. Mouse anti-beta actin was from ThermoFisher (Waltham, MA).

\section{Histology and Immunohistochemistry staining}

Formalin-fixed paraffin-embedded (FFPE) blocks of mouse livers were prepared from empty vector, BDD and N6-transduced mice. Tissue fixation and paraffin embedding was performed following routine methods. Serial sections of $4 \mu \mathrm{m}$-thick were cut from each FFPE block and adhered to charged glass slides (Superfrost Plus; Fisher Scientific, Waltham, MA, USA). Sections 
were incubated at $60^{\circ} \mathrm{C}$ for $1 \mathrm{hr}$ prior to deparaffinization in xylene and then rehydrated in $100 \%$, $95 \%$, and double-distilled water $\left(\mathrm{ddH}_{2} \mathrm{O}\right)$, successively. Sections were heat-induced in retrieval buffer at pH 6.0, incubated with peroxidase block (Dako, Mississauga, ON, Canada) for 20 min followed by blocking ( $5 \%$ goat serum in 1\% PBS-T) for $1 \mathrm{hr}$. Sections were then incubated overnight at $4^{\circ} \mathrm{C}$ with primary antibodies diluted in blocking buffer. Primary antibodies used for this study were: rabbit anti-GLUL (Glutamine Synthetase: Abcam, Cambridge, UK, ab176562; dilution 1:1000), rabbit anti-CD34 (Abcam, Cambridge, UK, ab81289; dilution 1:2500), rabbit antiCTNNB1 ( $\beta$-catenin: Abcam, Cambridge, UK, ab223075; dilution 1:4800), rabbit anti-CD44 (Abcam, Cambridge, UK, ab157107; dilution 1:2500), rabbit anti-GPC3 (Glypican-3: LSBio, Seattle, USA, LS-B13373; dilution 1:4000), rabbit anti-BiP (Binding Immunoglobulin Protein: Cell Signaling Technology, Massachusetts, USA, \#3177; dilution 1:600). The detection system used was the EnVision+ System-HRP kit (Dako, K4007). Sections were counterstained with hematoxylin prior to dehydration and mounted with Permount (Fisher, SP-15-100). The first section of each series was stained with Hematoxylin and Eosin (H\&E) and the fifth section was stained with reticulin (Abcam, \#ab150684) for an initial histopathological assessment. Immunohistochemistry with Thio-S and FVIII antibodies was performed as previously described (4).

\section{Scoring analysis}

Slides were scanned using the Aperio AT Turbo system at 20x magnification and viewed using the Aperio Image Scope system. The positivity [Total number of positive pixels divided by total number of pixels: (NTotal - Nn)/(NTotal)] was assessed using the positive pixel count algorithm from the ImageScope software (positive pixel count V9, Aperio, Inc.). The algorithm outputs a strong, moderate and weak intensity range. The total signal positivity was used to quantify all immunohistochemistry markers where only the strong signal positivity was used as a measure of total positivity of apoptotic cells for TUNEL assay positivity quantification. Signal positivity was analyzed at the central tumor, the interface and distal normal liver.

\section{Histopathological analysis}

All slides were analyzed, in a blinded fashion, by a board-certified pathologist who evaluated the presence of hepatocellular adenomas and carcinomas. The following are the stains used to confirm the lesions and also to evaluate whether they represent adenomas (benign disease) or carcinoma. Reticulin staining is intended to demonstrate reticular fibers surrounding tumor cells. Tumors that retain a reticulin network are generally benign or pre-neoplastic, whereas HCC loses the reticulin fiber normal architecture (61). CD34 is a marker of "capillarization", a process by 
which sinusoid endothelial cells lose their fenestration. CD34 demonstrates neovascularization in HCC, while nontumorous hepatic sinusoids do not stain with CD34 (62). However, it was previously reported that in some cases, CD34 may occur diffusely or in areas of hepatocellular adenoma (Brunt et al., 2012). Glutamine synthetase (GS) stains positively for zone 3 of the liver parenchyma. HCCs show strong positive staining while adenomas show negative staining. Similarly, glypican 3 (GPC3) was identified as a tumor marker for the diagnosis of HCC due to its specificity and sensitivity (46). GPC3 stains negatively hepatocellular carcinoma. $\beta$ catenin shows membranous positive staining on normal hepatocytes. Activation of $\beta$-catenin due to a missense mutation leads to cytoplasmic and nuclear accumulation of $\beta$-catenin which is suggestive of malignant transformation (63). Finally, CD44 is an adhesion molecule widely found on lymphoid and Kupffer cell types in normal liver (64). During malignant transformation, CD44 is upregulated in HCC progenitor cells and is a marker for tumor-initiating stem-like cells (65). HCC lesions that show a membranous staining pattern are indicative of neoplastic stem cell proliferation (66).

\section{Statistical Analyses}

Statistical analyses were performed using GraphPad Prism 9. Chi-square test was used for comparing of tumor incidence between BDD and N6 groups. A p value $<0.05$ was regarded as statistically significant. Statistical analysis for immunohistochemistry was performed with a twotailed Student's $t$-test. $P$ values of $<0.05$ were considered significant $\left(p<0.05^{*}, p<0.01^{* *}, p<\right.$ $\left.0.001^{* * *}\right)$.

\section{Acknowledgments}

This work was supported by NIH grants CA198103 and DK113171 to R.J.K. and in part by the NIDDK-funded San Diego Digestive Diseases Research Center (P30DK 120515). 


\section{Figure Legends}

Figure 1. A summary of hepatocyte responses to wtFVIII, BDD and N6 upon hydrodynamic tail vein injection of vector DNA into mice. FVIII secretion efficiency, activation of the UPR, activation of the systemic inflammatory response (INF), production of reactive oxygen species (ROS), induction of cell death, hepatic steatosis, the ability for BHA to prevent toxic responses. N/A: not applicable. a1-3=acidic regions. Red bracket indicates residues from the B domain of wtFVIII that were retained in N6. SQ-BDD/FVIII-SQ (Refacto, Pfizer), which is an effective protein replacement therapy for HA patients and used in the HA gene therapy clinical trials, contains an extra 14 amino acid linker (SFSQNPPVLKRHQR) at the junction between A2 and A3 domains of BDD.

Figure 2. A) FVIII aggregates induced by glucose depletion begin to resolve as early as $1 \mathrm{hr}$ following glucose repletion. $\mathrm{CHO}$ cells that express BDD or N6 were treated with either normal media or glucose-free media containing $10 \mathrm{mM} 2 \mathrm{DG}$ and $20 \mathrm{mM}$ azide $\left(2 \mathrm{DG}+\mathrm{NaN}_{3}\right)$. After $2 \mathrm{hr}$, cells were harvested or allowed to recover in complete media for the indicated times, or complete media with $10 \mathrm{mg} / \mathrm{ml} \mathrm{CHX}$. Cell lysates were filtered through nitrocellulose (left) or cellulose acetate (right) membranes and probed with FVIII or $\beta$-actin antibodies. Analysis of $\beta$-actin is from BDD expressing $\mathrm{CHO}$ cells. B) Reversible retention and secretion of active FVIII in $\mathrm{CHO}$ cells. $\left[{ }^{35} \mathrm{~S}\right] \mathrm{met} / \mathrm{cys}$ pulse-chase and aPTT analysis of BDD and $\mathrm{N} 6$ expressed in $\mathrm{CHO}$ cells. $\mathrm{CHO}$ cells were treated in parallel as in Panel A. CHO cells were pulse-labeled for 20 min and then chased for $20 \mathrm{~min}$ with media containing excess unlabeled met/cys to complete synthesis of nascent chains (lane 1) before being treated with either normal media (lanes 2-3) or glucose-free media containing $10 \mathrm{mM} 2 \mathrm{DG}$ and $20 \mathrm{mM} \mathrm{NaN}_{3}$. After $2 \mathrm{hr}$, cells were harvested (lane 4) or allowed to recover in complete media for increasing times (lanes 5-8), or complete media with CHX (lane 9). Lysates and media were collected at indicated time points for FVIII immunoprecipitation and reducing SDS-PAGE. For FVIII aPPT activity assay of media, cells were treated in parallel, but not pulse-labeled. Lanes: 1: Untreated, 20' chase; 2: Untreated 120' chase; 3: Untreated 240' chase; 4-9: 2DG for 120'; 5: 2-DG + 30' recovery; 6: 2-DG + 60' recovery; 7: 2DG + 120' recovery; 8: $2 D G+240$ ' recovery; 9: $2 D G+240$ ' recovery $+\mathrm{CHX}$.

Figure 3: BDD expression in hepatocytes in vivo causes accumulation of amyloid-like aggregates demonstrated by colocalization of FVIII (red) and thioflavin S (Thio-S) (green) stains in liver sections of BDD vector-injected mice. 
Figure 4. Epitope-tagging of the endogenous murine BIP/GRP78/Hspa5 locus demonstrates misfolding of BDD in vivo. A: A diagram illustrating the location of insertion of $3 x$ FLAG tag to Cterminal region of $\mathrm{BiP}$; $\mathrm{B}$ : Western blot demonstrating similar changes in hepatic levels of wildtype BiP (BiP) and BiP-FLAG in mice heterozygous for BiP-Flag allele (BiP-Flag ${ }^{+-} ; 10$ days after activation of BiP-FLAG expression in the liver) in response to treatment with tunicamycin for 24 h. C. Co-immunoprecipitation (IP) of BDD (lanes 13 \&14) and N6 (lanes 17 \& 18) from liver lysates of BDD or N6 vector-injected BiP-Flag homozygous mice $\left(\right.$ BiP-Flag $\left.^{+/+}\right)$with anti-FLAG magnetic beads. Direct FVIII IP using anti-FVIII agarose beads demonstrates the relative levels of BDD and N6 in the liver samples (lanes 21-24).

Figure 5. BDD expression induces the UPR in primary human hepatocytes $(\mathrm{PHH})$. $\mathrm{PHH}$ were transduced with a lentiviral vector expressing a codon-optimized form of SQ-BDD (Lenti-BDD) at the indicated vector doses and cultured in a hepatocyte-defined medium. The transduced $\mathrm{PHH}$ were harvested for western blot analysis 10 days post-transduction. Each lane represents individual culture well. The numerical numbers represent averaged fold changes after correction with loading control $\beta$-actin.

Figure 6. Transient expression of BDD or N6 in the murine hepatocytes through hydrodynamic tail veil injection of vector NDA induced liver tumors following a long-term high-fat diet feeding. A: Plasma levels of FVIII. WT C57BL/6J mice were injected with pMT empty vector, N6 or BDD vectors by hydrodynamic tail vein injection. After $24 \mathrm{~h}$, plasma was obtained and FVIII levels were measured by ELISA. Data shown are Mean $\pm \mathrm{SE}(\mathrm{N}=4$ for pMT-empty vector and $\mathrm{BDD}, \mathrm{N}=5$ for N6). One way ANOVA was used for statistical analysis. B: Incidence of tumors summary and the difference between the two groups (N6 \& BDD) were tested for statistical significance using the Chi-square test (degrees of freedom $=1,95 \%$ confidence intervals). C: Total number of adenoma and $\mathrm{HCC}$ incidence (\%) for the BDD cohort.

Figure 7. Total Positivity levels (\%) of BiP quantification of FVIII-N6 and FVIII-BDD mouse cohorts. Central tumor, interface normal, and distal normal regions of interest are quantified using the total positive pixel per count algorithm from Aperio software represented as positivity percentage (pixels/Area). A: Comparison of positivity (\%) levels of adenoma and HCC tumor types for N6 and BDD cohorts. B: Comparison of positivity (\%) levels of N6 and BDD cohorts for adenoma and HCC tumor types. Statistical analyses were performed using a two-tailed Student's t-test where $P$ values of $<0.05$ were considered to be significant $\left(p<0.05^{*}, p<0.01^{* *}\right.$, $\left.\mathrm{p}<0.001^{* * *}\right)$. 
Figure 8. Representation of BiP immunohistochemistry. FVIII-N6 and FVIII-BDD cohort samples (N6-5, N6-9, BDD-1, and BDD-3) for Adenoma and HCC

Figure S1. A: Plasma levels of FVIII. WT C57BL/6J mice were injected with pMT empty vector, $\mathrm{N} 6$ of BDD vectors by hydrodynamic tail vein injection. After $24 \mathrm{~h}$, plasma was obtained and FVIII levels were measured by ELISA. Data shown are Mean $\pm S E(N=4$ for pMT-empty vector and BDD, $\mathrm{N}=5$ for N6) One way ANOVA was used for statistical analysis. B: Incidence of tumors summary and the difference between the two groups (N6 \& BDD) were tested for statistical significance using the Chi-square test (degrees of freedom $=1,95 \%$ confidence intervals). C: Total number of adenoma and HCC incidence (\%) for the N6 cohort.

Figure S2. Immunohistochemistry characterization of two (N6-2 and BDD8) HCC samples. Serial sections are stained for H\&E: Hematoxylin and Eosin, reticulin, CD34, glutamine synthetase, glypican-3, Beta-catenin, and CD44.

Figure S3. Immunohistochemistry characterization of Bip of two (N6-2 and BDD8) HCC samples

Table S1. Immunohistochemistry characterization of the FVIII-N6 cohort samples.

Table S2. Immunohistochemistry characterization of the FVIII-BDD cohort samples. 


\section{References}

1. Pittman DD, Kaufman RJ. Structure-function relationships of factor VIII elucidated through recombinant DNA technology. Thrombosis and haemostasis. 1989;61(2):161-5. PubMed PMID: 2501893.

2. Everett LA, Cleuren AC, Khoriaty RN, Ginsburg D. Murine coagulation factor VIII is synthesized in endothelial cells. Blood. 2014;123(24):3697-705. Epub 2014/04/11. doi: 10.1182/blood-2014-02-554501. PubMed PMID: 24719406; PMCID: PMC4055920. 3. Toole JJ, Pittman DD, Orr EC, Murtha P, Wasley LC, Kaufman RJ. A large region (approximately equal to $95 \mathrm{kDa}$ ) of human factor VIII is dispensable for in vitro procoagulant activity. Proc Natl Acad Sci U S A. 1986;83(16):5939-42. PubMed PMID: 3016730; PMCID: 386412.

4. Pittman DD, Alderman EM, Tomkinson KN, Wang JH, Giles AR, Kaufman RJ. Biochemical, immunological, and in vivo functional characterization of B-domain-deleted factor VIII. Blood. 1993;81(11):2925-35. Epub 1993/06/01. PubMed PMID: 8499631.

5. Di Paola J, Smith MP, Klamroth R, Mannucci PM, Kollmer C, Feingold J, Kessler C, Pollmann H, Morfini M, Udata C, Rothschild C, Hermans C, Janco R. ReFacto and Advate: a single-dose, randomized, two-period crossover pharmacokinetics study in subjects with haemophilia A. Haemophilia. 2007;13(2):124-30. Epub 2007/02/09. doi: 10.1111/j.13652516.2006.01420.x. PubMed PMID: 17286764.

6. Lusher JM, Lee CA, Kessler CM, Bedrosian CL, ReFacto Phase 3 Study G. The safety and efficacy of B-domain deleted recombinant factor VIII concentrate in patients with severe haemophilia A. Haemophilia. 2003;9(1):38-49. Epub 2003/02/01. doi: 10.1046/j.13652516.2003.00708.x. PubMed PMID: 12558777.

7. Lusher JM, Roth DA. The safety and efficacy of B-domain deleted recombinant factor VIII concentrates in patients with severe haemophilia A: an update. Haemophilia. 2005;11(3):292-3. Epub 2005/05/07. doi: 10.1111/j.1365-2516.2005.01099.x. PubMed PMID: 15876278.

8. Ward NJ, Buckley SM, Waddington SN, Vandendriessche T, Chuah MK, Nathwani AC, McIntosh J, Tuddenham EG, Kinnon C, Thrasher AJ, McVey JH. Codon optimization of human factor VIII cDNAs leads to high-level expression. Blood. 2011;117(3):798-807. Epub

2010/11/03. doi: 10.1182/blood-2010-05-282707. PubMed PMID: 21041718.

9. Rangarajan S, Walsh L, Lester W, Perry D, Madan B, Laffan M, Yu H, Vettermann C, Pierce GF, Wong WY, Pasi KJ. AAV5-Factor VIII Gene Transfer in Severe Hemophilia A. N Engl J Med. 2017;377(26):2519-30. Epub 2017/12/12. doi: 10.1056/NEJMoa1708483. PubMed PMID: 29224506.

10. Pasi KJ, Rangarajan S, Mitchell N, Lester W, Symington E, Madan B, Laffan M, Russell CB, Li M, Pierce GF, Wong WY. Multiyear Follow-up of AAV5-hFVIII-SQ Gene Therapy for Hemophilia A. N Engl J Med. 2020;382(1):29-40. Epub 2020/01/02. doi: 10.1056/NEJMoa1908490. PubMed PMID: 31893514.

11. Grimm D, Kay MA. From virus evolution to vector revolution: use of naturally occurring serotypes of adeno-associated virus (AAV) as novel vectors for human gene therapy. Curr Gene Ther. 2003;3(4):281-304. Epub 2003/07/23. doi: 10.2174/1566523034578285. PubMed PMID: 12871018.

12. Arruda VR, Doshi BS. Gene Therapy for Hemophilia: Facts and Quandaries in the 21st Century. Mediterr J Hematol Infect Dis. 2020;12(1):e2020069. Epub 2020/09/22. doi: 10.4084/MJHID.2020.069. PubMed PMID: 32952980; PMCID: PMC7485465.

13. Malhotra JD, Miao H, Zhang K, Wolfson A, Pennathur S, Pipe SW, Kaufman RJ. Antioxidants reduce endoplasmic reticulum stress and improve protein secretion. Proc Natl Acad Sci U S A. 2008;105(47):18525-30. Epub 2008/11/18. doi: 10.1073/pnas.0809677105. 
PubMed PMID: 19011102; PMCID: PMC2587584.

14. Nichols WC, Seligsohn U, Zivelin A, Terry VH, Hertel CE, Wheatley MA, Moussalli MJ, Hauri HP, Ciavarella N, Kaufman RJ, Ginsburg D. Mutations in the ER-Golgi intermediate compartment protein ERGIC-53 cause combined deficiency of coagulation factors $\mathrm{V}$ and VIII. Cell. 1998;93(1):61-70. Epub 1998/04/18. doi: 10.1016/s0092-8674(00)81146-0. PubMed PMID: 9546392.

15. Pipe SW, Morris JA, Shah J, Kaufman RJ. Differential interaction of coagulation factor VIII and factor $\mathrm{V}$ with protein chaperones calnexin and calreticulin. J Biol Chem. 1998;273(14):8537-44. Epub 1998/05/09. doi: 10.1074/jbc.273.14.8537. PubMed PMID: 9525969.

16. Moussalli M, Pipe SW, Hauri HP, Nichols WC, Ginsburg D, Kaufman RJ. Mannosedependent endoplasmic reticulum (ER)-Golgi intermediate compartment-53-mediated ER to Golgi trafficking of coagulation factors V and VIII. J Biol Chem. 1999;274(46):32539-42. Epub 1999/11/07. doi: 10.1074/jbc.274.46.32539. PubMed PMID: 10551804.

17. Cunningham MA, Pipe SW, Zhang B, Hauri HP, Ginsburg D, Kaufman RJ. LMAN1 is a molecular chaperone for the secretion of coagulation factor VIII. J Thromb Haemost.

2003;1(11):2360-7. Epub 2003/11/25. doi: 10.1046/j.1538-7836.2003.00415.x. PubMed PMID: 14629470.

18. Zhang B, Cunningham MA, Nichols WC, Bernat JA, Seligsohn U, Pipe SW, McVey JH, Schulte-Overberg U, de Bosch NB, Ruiz-Saez A, White GC, Tuddenham EG, Kaufman RJ, Ginsburg D. Bleeding due to disruption of a cargo-specific ER-to-Golgi transport complex. Nat Genet. 2003;34(2):220-5. Epub 2003/04/30. doi: 10.1038/ng1153. PubMed PMID: 12717434. 19. Zhang B, McGee B, Yamaoka JS, Guglielmone H, Downes KA, Minoldo S, Jarchum G, Peyvandi F, de Bosch NB, Ruiz-Saez A, Chatelain B, Olpinski M, Bockenstedt P, Sperl W, Kaufman RJ, Nichols WC, Tuddenham EG, Ginsburg D. Combined deficiency of factor V and factor VIII is due to mutations in either LMAN1 or MCFD2. Blood. 2006;107(5):1903-7. Epub 2005/11/24. doi: 10.1182/blood-2005-09-3620. PubMed PMID: 16304051; PMCID: PMC1895703.

20. Miao HZ, Sirachainan N, Palmer L, Kucab P, Cunningham MA, Kaufman RJ, Pipe SW. Bioengineering of coagulation factor VIII for improved secretion. Blood. 2004;103(9):3412-9. Epub 2004/01/17. doi: 10.1182/blood-2003-10-3591. PubMed PMID: 14726380.

21. Poothong J, Pottekat A, Siirin M, Campos AR, Paton AW, Paton JC, Lagunas-Acosta J, Chen Z, Swift M, Volkmann N, Hanein D, Yong J, Kaufman RJ. Factor VIII exhibits chaperonedependent and glucose-regulated reversible amyloid formation in the endoplasmic reticulum. Blood. 2020;135(21):1899-911. Epub 2020/03/05. doi: 10.1182/blood.2019002867. PubMed PMID: 32128578; PMCID: PMC7243144.

22. Sabatino DE. Clogging up the pipeline: factor VIII aggregates. Blood. 2020;135(21):1825-7. Epub 2020/05/22. doi: 10.1182/blood.2020005450. PubMed PMID: 32437559.

23. Pasi KJ, Laffan M, Rangarajan S, Robinson TM, Mitchell N, Lester W, Symington E, Madan B, Yang X, Kim B, Pierce GF, Wong WY. Persistence of haemostatic response following gene therapy with valoctocogene roxaparvovec in severe haemophilia A. Haemophilia. 2021. Epub 2021/08/12. doi: 10.1111/hae.14391. PubMed PMID: 34378280.

24. Pierce GF. Gene Therapy for Hemophilia: Are Expectations Matching Reality? Mol Ther. 2020;28(10):2097-8. Epub 2020/09/24. doi: 10.1016/j.ymthe.2020.09.019. PubMed PMID: 32966774; PMCID: PMC7544995.

25. Pierce GF, Kaczmarek R, Noone D, O'Mahony B, Page D, Skinner MW. Gene therapy to cure haemophilia: Is robust scientific inquiry the missing factor? Haemophilia. 2020;26(6):931-3. Epub 2020/09/11. doi: 10.1111/hae.14131. PubMed PMID: 32909632.

26. Sheridan C. A reprieve from hemophilia A, but for how long? Nat Biotechnol. 2020;38(10):1107-9. Epub 2020/10/07. doi: 10.1038/s41587-020-0693-y. PubMed PMID: 
33020631.

27. Batty P, Lillicrap D. Hemophilia Gene Therapy: Approaching the First Licensed Product. Hemasphere. 2021;5(3):e540. Epub 2021/02/20. doi: 10.1097/HS9.0000000000000540. PubMed PMID: 33604517; PMCID: PMC7886458 PB has received research support from BioMarin, Grifols, and Octapharma.

28. White DL, Thrift AP, Kanwal F, Davila J, El-Serag HB. Incidence of Hepatocellular Carcinoma in All 50 United States, From 2000 Through 2012. Gastroenterology.

2017;152(4):812-20 e5. Epub 2016/11/28. doi: 10.1053/j.gastro.2016.11.020. PubMed PMID: 27889576; PMCID: PMC5346030.

29. Younossi Z, Tacke F, Arrese M, Chander Sharma B, Mostafa I, Bugianesi E, Wai-Sun Wong V, Yilmaz Y, George J, Fan J, Vos MB. Global Perspectives on Nonalcoholic Fatty Liver Disease and Nonalcoholic Steatohepatitis. Hepatology. 2019;69(6):2672-82. Epub 2018/09/05. doi: 10.1002/hep.30251. PubMed PMID: 30179269.

30. Wang M, Kaufman RJ. The impact of the endoplasmic reticulum protein-folding environment on cancer development. Nat Rev Cancer. 2014;14(9):581-97. Epub 2014/08/26. doi: 10.1038/nrc3800. PubMed PMID: 25145482.

31. Wang M, Kaufman RJ. Protein misfolding in the endoplasmic reticulum as a conduit to human disease. Nature. 2016;529(7586):326-35. Epub 2016/01/23. doi: 10.1038/nature17041. PubMed PMID: 26791723.

32. Malhi H, Kaufman RJ. Endoplasmic reticulum stress in liver disease. J Hepatol. 2011;54(4):795-809. Epub 2010/12/15. doi: 10.1016/j.jhep.2010.11.005. PubMed PMID: 21145844; PMCID: PMC3375108.

33. Lebeaupin C, Vallee D, Hazari Y, Hetz C, Chevet E, Bailly-Maitre B. Endoplasmic reticulum stress signalling and the pathogenesis of non-alcoholic fatty liver disease. $J$ Hepatol. 2018;69(4):927-47. Epub 2018/06/26. doi: 10.1016/j.jhep.2018.06.008. PubMed PMID: 29940269.

34. Rutkowski DT. Liver function and dysfunction - a unique window into the physiological reach of ER stress and the unfolded protein response. FEBS J. 2019;286(2):356-78. Epub 2018/01/24. doi: 10.1111/febs.14389. PubMed PMID: 29360258; PMCID: PMC6056347. 35. Nakagawa H, Umemura A, Taniguchi K, Font-Burgada J, Dhar D, Ogata H, Zhong Z, Valasek MA, Seki E, Hidalgo J, Koike K, Kaufman RJ, Karin M. ER stress cooperates with hypernutrition to trigger TNF-dependent spontaneous HCC development. Cancer Cell. 2014;26(3):331-43. Epub 2014/08/19. doi: 10.1016/j.ccr.2014.07.001. PubMed PMID: 25132496; PMCID: PMC4165611.

36. Liu F, Song Y, Liu D. Hydrodynamics-based transfection in animals by systemic administration of plasmid DNA. Gene Ther. 1999;6(7):1258-66. Epub 1999/08/24. doi: 10.1038/sj.gt.3300947. PubMed PMID: 10455434.

37. Pobre KFR, Poet GJ, Hendershot LM. The endoplasmic reticulum (ER) chaperone BiP is a master regulator of ER functions: Getting by with a little help from ERdj friends. J Biol Chem. 2019;294(6):2098-108. Epub 2018/12/20. doi: 10.1074/jbc.REV118.002804. PubMed PMID: 30563838; PMCID: PMC6369273.

38. $\mathrm{Ng}$ DT, Watowich SS, Lamb RA. Analysis in vivo of GRP78-BiP/substrate interactions and their role in induction of the GRP78-BiP gene. Mol Biol Cell. 1992;3(2):143-55. Epub 1992/02/01. doi: 10.1091/mbc.3.2.143. PubMed PMID: 1550958; PMCID: PMC275514. 39. Preissler S, Chambers JE, Crespillo-Casado A, Avezov E, Miranda E, Perez J, Hendershot LM, Harding HP, Ron D. Physiological modulation of BiP activity by trans-protomer engagement of the interdomain linker. Elife. 2015;4:e08961. Epub 2015/10/17. doi:

10.7554/eLife.08961. PubMed PMID: 26473973; PMCID: PMC4608358.

40. Peng Y, Chen Z, Peter A, Kaufman RJ. Epitope-tagging of the endogenous murine $\mathrm{BiP} / \mathrm{GRP} 78 / \mathrm{Hspa} 5$ locus allows direct analysis of the BiP interactome and protein misfolding in vivo. bioRxiv. 2020:2020.01.01.892539. doi: 10.1101/2020.01.01.892539. 
41. Michailidis E, Vercauteren K, Mancio-Silva L, Andrus L, Jahan C, Ricardo-Lax I, Zou C, Kabbani M, Park P, Quirk C, Pyrgaki C, Razooky B, Verhoye L, Zoluthkin I, Lu WY, Forbes SJ, Chiriboga L, Theise ND, Herzog RW, Suemizu H, Schneider WM, Shlomai A, Meuleman P, Bhatia SN, Rice CM, de Jong YP. Expansion, in vivo-ex vivo cycling, and genetic manipulation of primary human hepatocytes. Proc Natl Acad Sci U S A. 2020;117(3):1678-88. Epub 2020/01/10. doi: 10.1073/pnas.1919035117. PubMed PMID: 31915293; PMCID: PMC6983380. 42. Vecchi C, Montosi G, Zhang K, Lamberti I, Duncan SA, Kaufman RJ, Pietrangelo A. ER stress controls iron metabolism through induction of hepcidin. Science. 2009;325(5942):877-80. Epub 2009/08/15. doi: 10.1126/science.1176639. PubMed PMID: 19679815; PMCID: PMC2923557.

43. Oh-hashi K, Koga H, Ikeda S, Shimada K, Hirata Y, Kiuchi K. CRELD2 is a novel endoplasmic reticulum stress-inducible gene. Biochem Biophys Res Commun.

2009;387(3):504-10. Epub 2009/07/21. doi: 10.1016/j.bbrc.2009.07.047. PubMed PMID: 19615339.

44. Boyle ST, Poltavets V, Kular J, Pyne NT, Sandow JJ, Lewis AC, Murphy KJ, Kolesnikoff N, Moretti PAB, Tea MN, Tergaonkar V, Timpson P, Pitson SM, Webb Al, Whitfield RJ, Lopez AF, Kochetkova M, Samuel MS. Publisher Correction: ROCK-mediated selective activation of PERK signalling causes fibroblast reprogramming and tumour progression through a CRELD2dependent mechanism. Nat Cell Biol. 2020;22(7):908. Epub 2020/06/06. doi: 10.1038/s41556020-0539-3. PubMed PMID: 32499616.

45. Cui S, Hano H, Sakata A, Harada T, Liu T, Takai S, Ushigome S. Enhanced CD34 expression of sinusoid-like vascular endothelial cells in hepatocellular carcinoma. Pathol Int. 1996;46(10):751-6. Epub 1996/10/01. doi: 10.1111/j.1440-1827.1996.tb03544.x. PubMed PMID: 8916144.

46. Wasfy RE, Shams Eldeen AA. Roles of Combined Glypican-3 and Glutamine Synthetase in Differential Diagnosis of Hepatocellular Lesions. Asian Pac J Cancer Prev. 2015;16(11):4769-75. Epub 2015/06/25. doi: 10.7314/apjcp.2015.16.11.4769. PubMed PMID: 26107238.

47. Di Tommaso L, Franchi G, Park YN, Fiamengo B, Destro A, Morenghi E, Montorsi M, Torzilli G, Tommasini M, Terracciano L, Tornillo L, Vecchione R, Roncalli M. Diagnostic value of HSP70, glypican 3, and glutamine synthetase in hepatocellular nodules in cirrhosis. Hepatology. 2007;45(3):725-34. Epub 2007/02/28. doi: 10.1002/hep.21531. PubMed PMID: 17326147.

48. Sidonio RF, Jr., Pipe SW, Callaghan MU, Valentino LA, Monahan PE, Croteau SE. Discussing investigational AAV gene therapy with hemophilia patients: A guide. Blood Rev. 2020:100759. Epub 2020/11/14. doi: 10.1016/j.blre.2020.100759. PubMed PMID: 33183859.

49. Kaiser J. How safe is a popular gene therapy vector? Science. 2020;367(6474):131. Epub 2020/01/11. doi: 10.1126/science.367.6474.131. PubMed PMID: 31919200.

50. Fong S, Handyside B, Sihn CR, Liu S, Zhang L, Xie L, Murphy R, Galicia N, Yates B, Minto WC, Vitelli C, Harmon D, Ru Y, Yu GK, Escher C, Vowinckel J, Woloszynek J, Akeefe H, Mahimkar R, Bullens S, Bunting S. Induction of ER Stress by an AAV5 BDD FVIII Construct Is Dependent on the Strength of the Hepatic-Specific Promoter. Mol Ther Methods Clin Dev. 2020;18:620-30. Epub 2020/08/11. doi: 10.1016/j.omtm.2020.07.005. PubMed PMID: 32775496; PMCID: PMC7397702.

51. Karin M, Cao Y, Greten FR, Li ZW. NF-kappaB in cancer: from innocent bystander to major culprit. Nat Rev Cancer. 2002;2(4):301-10. Epub 2002/05/11. doi: 10.1038/nrc780. PubMed PMID: 12001991.

52. Rutkowski DT, Wu J, Back SH, Callaghan MU, Ferris SP, lqbal J, Clark R, Miao H, Hassler JR, Fornek J, Katze MG, Hussain MM, Song B, Swathirajan J, Wang J, Yau GD, Kaufman RJ. UPR pathways combine to prevent hepatic steatosis caused by ER stressmediated suppression of transcriptional master regulators. Dev Cell. 2008;15(6):829-40. Epub 2008/12/17. doi: 10.1016/j.devcel.2008.10.015. PubMed PMID: 19081072; PMCID: 
PMC2923556.

53. Zhang K, Shen X, Wu J, Sakaki K, Saunders T, Rutkowski DT, Back SH, Kaufman RJ. Endoplasmic reticulum stress activates cleavage of $\mathrm{CREBH}$ to induce a systemic inflammatory response. Cell. 2006;124(3):587-99. Epub 2006/02/14. doi: 10.1016/j.cell.2005.11.040. PubMed PMID: 16469704.

54. de Jong YP, Herzog RW. Liver gene therapy and hepatocellular carcinoma: A complex web. Mol Ther. 2021;29(4):1353-4. Epub 2021/03/21. doi: 10.1016/j.ymthe.2021.03.009.

PubMed PMID: 33743193; PMCID: PMC8058499.

55. Dalwadi DA, Torrens L, Abril-Fornaguera J, Pinyol R, Willoughby C, Posey J, Llovet JM, Lanciault C, Russell DW, Grompe M, Naugler WE. Liver Injury Increases the Incidence of HCC following AAV Gene Therapy in Mice. Mol Ther. 2021;29(2):680-90. Epub 2021/02/09. doi: 10.1016/j.ymthe.2020.10.018. PubMed PMID: 33554867; PMCID: PMC7854305.

56. Febbraio MA, Reibe S, Shalapour S, Ooi GJ, Watt MJ, Karin M. Preclinical Models for Studying NASH-Driven HCC: How Useful Are They? Cell Metab. 2019;29(1):18-26. Epub 2018/11/20. doi: 10.1016/j.cmet.2018.10.012. PubMed PMID: 30449681; PMCID: PMC6326872.

57. Kim JY, He F, Karin M. From Liver Fat to Cancer: Perils of the Western Diet. Cancers (Basel). 2021;13(5). Epub 2021/04/04. doi: 10.3390/cancers13051095. PubMed PMID: 33806428; PMCID: PMC7961422.

58. Nguyen GN, Everett JK, Kafle S, Roche AM, Raymond HE, Leiby J, Wood C, Assenmacher CA, Merricks EP, Long CT, Kazazian HH, Nichols TC, Bushman FD, Sabatino DE. A long-term study of AAV gene therapy in dogs with hemophilia A identifies clonal expansions of transduced liver cells. Nat Biotechnol. 2021;39(1):47-55. Epub 2020/11/18. doi: 10.1038/s41587-020-0741-7. PubMed PMID: 33199875; PMCID: PMC7855056.

59. Lange AM, Altynova ES, Nguyen GN, Sabatino DE. Overexpression of factor VIII after AAV delivery is transiently associated with cellular stress in hemophilia A mice. Mol Ther Methods Clin Dev. 2016;3:16064. Epub 2016/10/16. doi: 10.1038/mtm.2016.64. PubMed PMID: 27738645; PMCID: PMC5040173.

60. Zolotukhin I, Markusic DM, Palaschak B, Hoffman BE, Srikanthan MA, Herzog RW. Potential for cellular stress response to hepatic factor VIII expression from AAV vector. Mol Ther Methods Clin Dev. 2016;3:16063. Epub 2016/10/16. doi: 10.1038/mtm.2016.63. PubMed PMID: 27738644; PMCID: PMC5040172.

61. Brunt EM. Histopathologic features of hepatocellular carcinoma. Clin Liver Dis (Hoboken). 2012;1(6):194-9. Epub 2013/01/23. doi: 10.1002/cld.98. PubMed PMID: 31186886; PMCID: PMC6499305.

62. Coston WM, Loera S, Lau SK, Ishizawa S, Jiang Z, Wu CL, Yen Y, Weiss LM, Chu PG. Distinction of hepatocellular carcinoma from benign hepatic mimickers using Glypican-3 and CD34 immunohistochemistry. Am J Surg Pathol. 2008;32(3):433-44. Epub 2008/02/28. doi: 10.1097/PAS.0b013e318158142f. PubMed PMID: 18300806.

63. Garcia-Buitrago MT. Beta-Catenin Staining of Hepatocellular Adenomas. Gastroenterol Hepatol (N Y). 2017;13(12):740-3. Epub 2018/01/18. PubMed PMID: 29339950; PMCID: PMC5763560.

64. Flanagan BF, Dalchau R, Allen AK, Daar AS, Fabre JW. Chemical composition and tissue distribution of the human CDw44 glycoprotein. Immunology. 1989;67(2):167-75. Epub 1989/06/01. PubMed PMID: 2666306; PMCID: PMC1385252.

65. Ji J, Wang XW. Clinical implications of cancer stem cell biology in hepatocellular carcinoma. Semin Oncol. 2012;39(4):461-72. Epub 2012/08/01. doi: 10.1053/j.seminoncol.2012.05.011. PubMed PMID: 22846863; PMCID: PMC3409471.

66. Basakran NS. CD44 as a potential diagnostic tumor marker. Saudi Med J.

2015;36(3):273-9. Epub 2015/03/05. doi: 10.15537/smj.2015.3.9622. PubMed PMID: 25737167; PMCID: PMC4381009. 


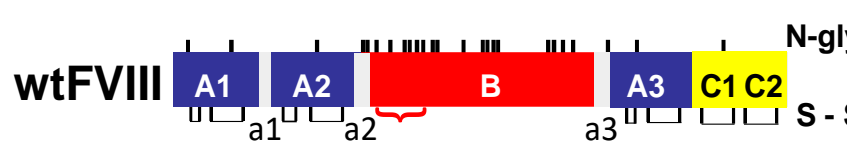
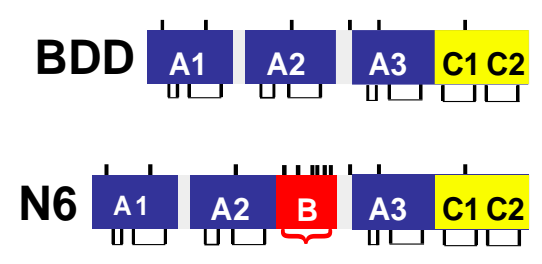

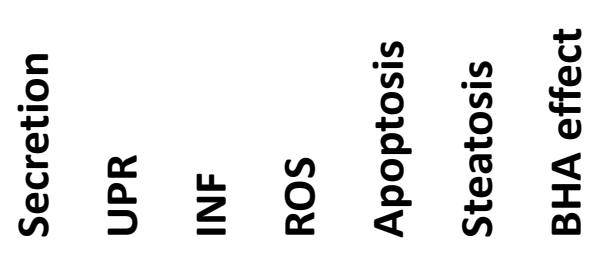

$10++++++$

$10++++++$

hi +/- ? +/- +/- +/- +/-

Figure 1. A summary of hepatocyte responses to wtFVIII, BDD and N6 upon hydrodynamic tail vein injection of vector DNA into mice. FVIII secretion efficiency, activation of the UPR, activation of the systemic inflammatory response (INF), production of reactive oxygen species (ROS), induction of cell death, hepatic steatosis, the ability for BHA to prevent toxic responses. N/A: not applicable. a1-3=acidic regions. Red bracket indicates residues from the B domain of wtFVIII that were retained in N6. SQ-BDD/FVIII-SQ (Refacto, Pfizer), which is an effective protein replacement therapy for HA patients and used in the HA gene therapy clinical trials, contains an extra 14 amino acid linker (SFSQNPPVLKRHQR) at the junction between $\mathrm{A} 2$ and $\mathrm{A} 3$ domains of BDD. 


\section{A FVIII aggregates induced by glucose depletion begin} to resolve as early as $\mathbf{1} \mathrm{hr}$ following glucose repletion.

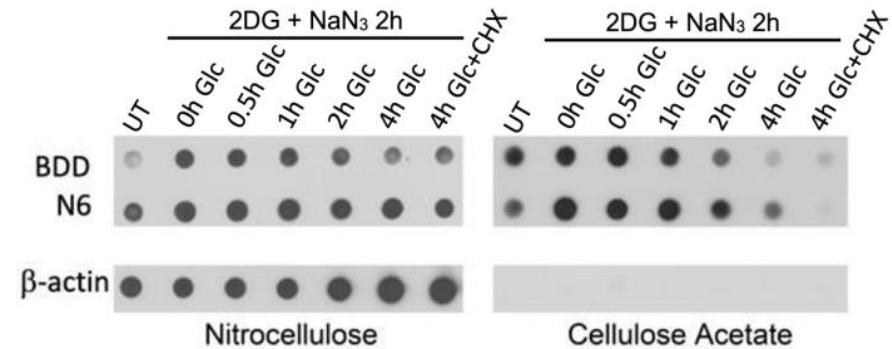
B Reversible retention and secretion of active
FVIII in CHO cells
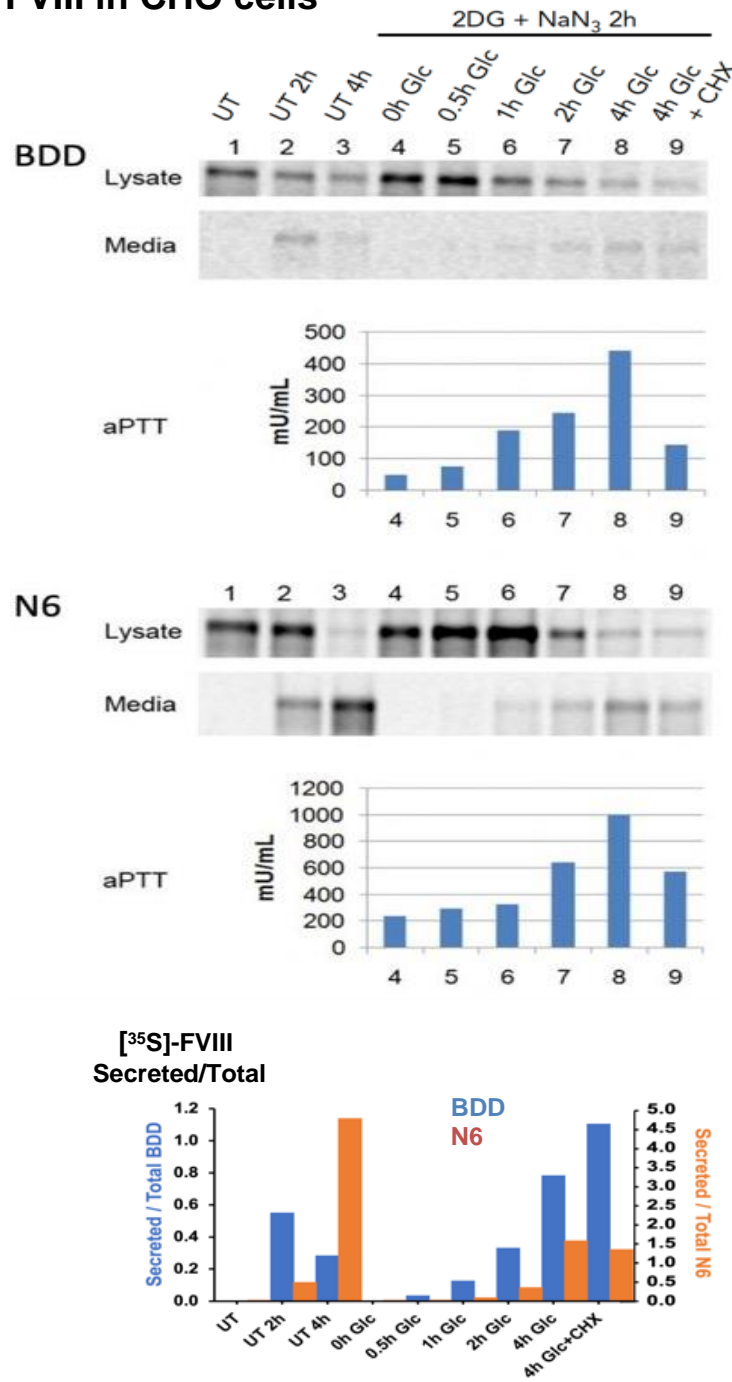

Figure 2. A) FVIII aggregates induced by glucose depletion begin to resolve as early as $1 \mathrm{hr}$ following glucose repletion. $\mathrm{CHO}$ cells that express $\mathrm{BDD}$ or N6 were treated with either normal media or glucose-free media containing $10 \mathrm{mM}$ 2DG and $20 \mathrm{mM}$ azide $\left(2 \mathrm{DG}+\mathrm{NaN}_{3}\right)$. After $2 \mathrm{hr}$, cells were harvested or allowed to recover in complete media for the indicated times, or complete media with $10 \mathrm{mg} / \mathrm{ml} \mathrm{CHX}$. Cell lysates were filtered through nitrocellulose (left) or cellulose acetate (right) membranes and probed with FVIII or $\beta$-actin antibodies. Analysis of $\beta$-actin is from BDD expressing $\mathrm{CHO}$ cells. B) Reversible retention and secretion of active FVIII in $\mathrm{CHO}$ cells. $\left[{ }^{35} \mathrm{~S}\right] \mathrm{met} / \mathrm{cys}$ pulse-chase and aPTT analysis of BDD and $\mathrm{N} 6$ expressed in $\mathrm{CHO}$ cells. $\mathrm{CHO}$ cells were treated in parallel as in Panel A. $\mathrm{CHO}$ cells were pulse-labeled for 20 min and then chased for 20 min with media containing excess unlabeled met/cys to complete synthesis of nascent chains (lane 1) before being treated with either normal media (lanes 2-3) or glucose-free media containing 10 $\mathrm{mM} 2 \mathrm{DG}$ and $20 \mathrm{mM} \mathrm{NaN}_{3}$. After $2 \mathrm{hr}$, cells were harvested (lane 4) or allowed to recover in complete media for increasing times (lanes 5-8), or complete media with $\mathrm{CHX}$ (lane 9). Lysates and media were collected at indicated time points for FVIII immunoprecipitation and reducing SDSPAGE. For FVIII aPPT activity assay of media, cells were treated in parallel, but not pulse-labeled. Lanes: 1: Untreated, 20' chase; 2: Untreated 120' chase; 3: Untreated 240' chase; 4-9: 2DG for 120'; 5: $2-D G+30$ recovery; $6: 2-D G+60$ ' recovery; 7: $2 D G+120$ ' recovery; 8 : $2 D G+240$ ' recovery; 9: $2 D G+240$ ' recovery $+\mathrm{CHX}$. 


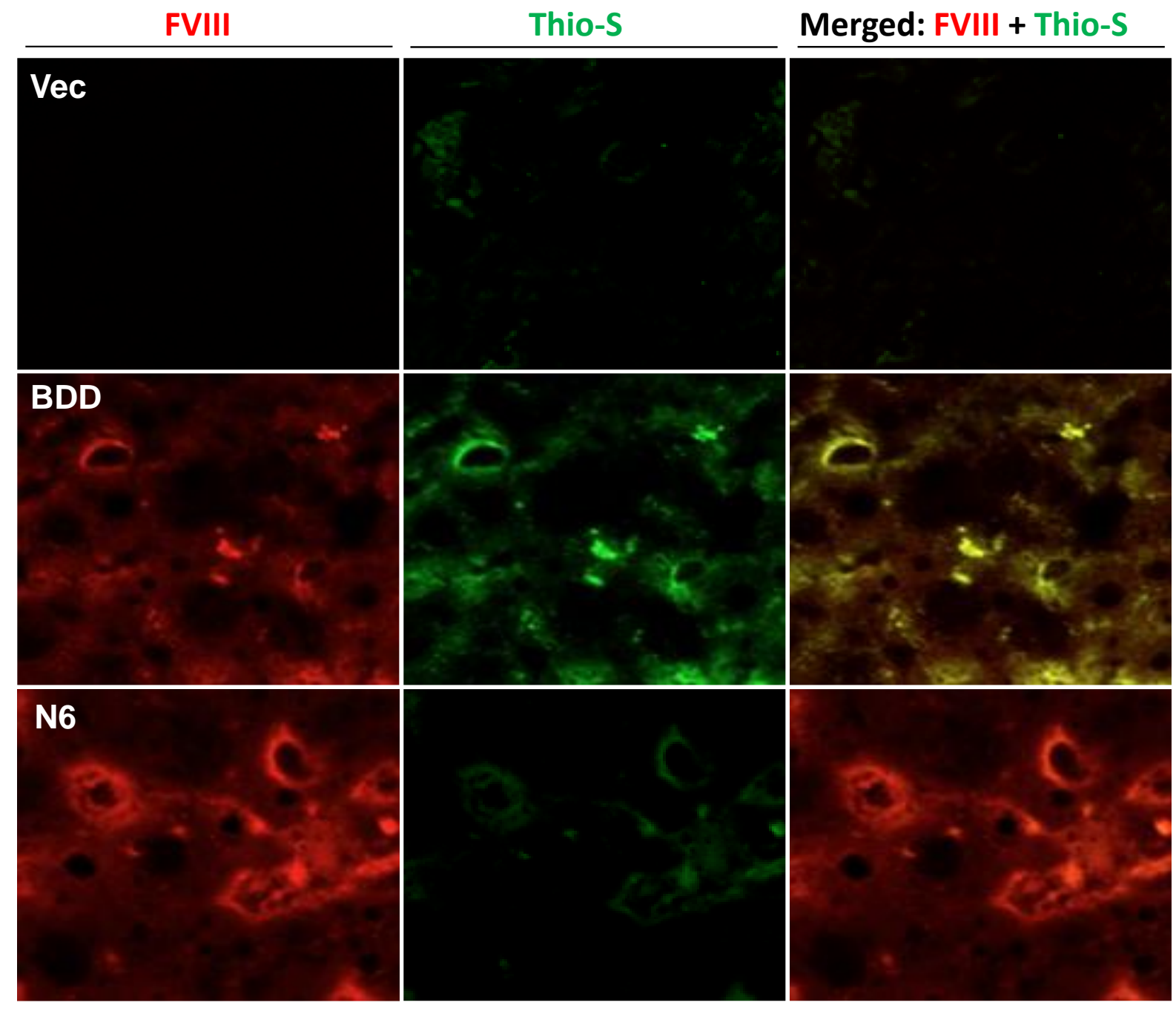

Figure 3: BDD expression in hepatocytes in vivo causes accumulation of amyloid-like aggregates demonstrated by colocalization of FVIII (red) and thioflavin S (Thio-S) (green) stains in liver sections of BDD vector-injected mice. 


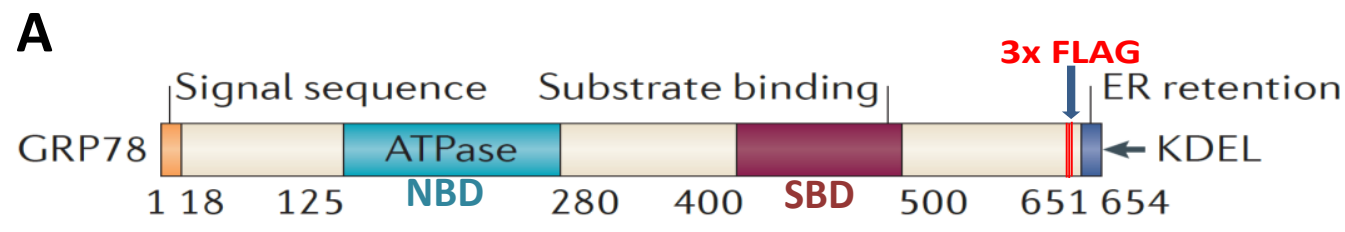

B

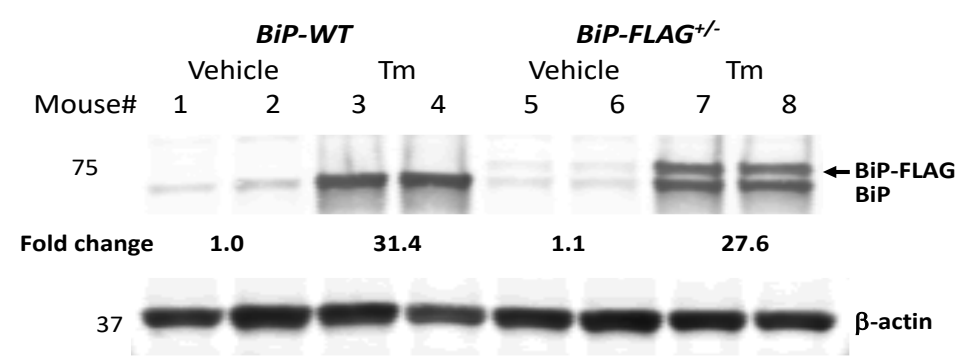

C
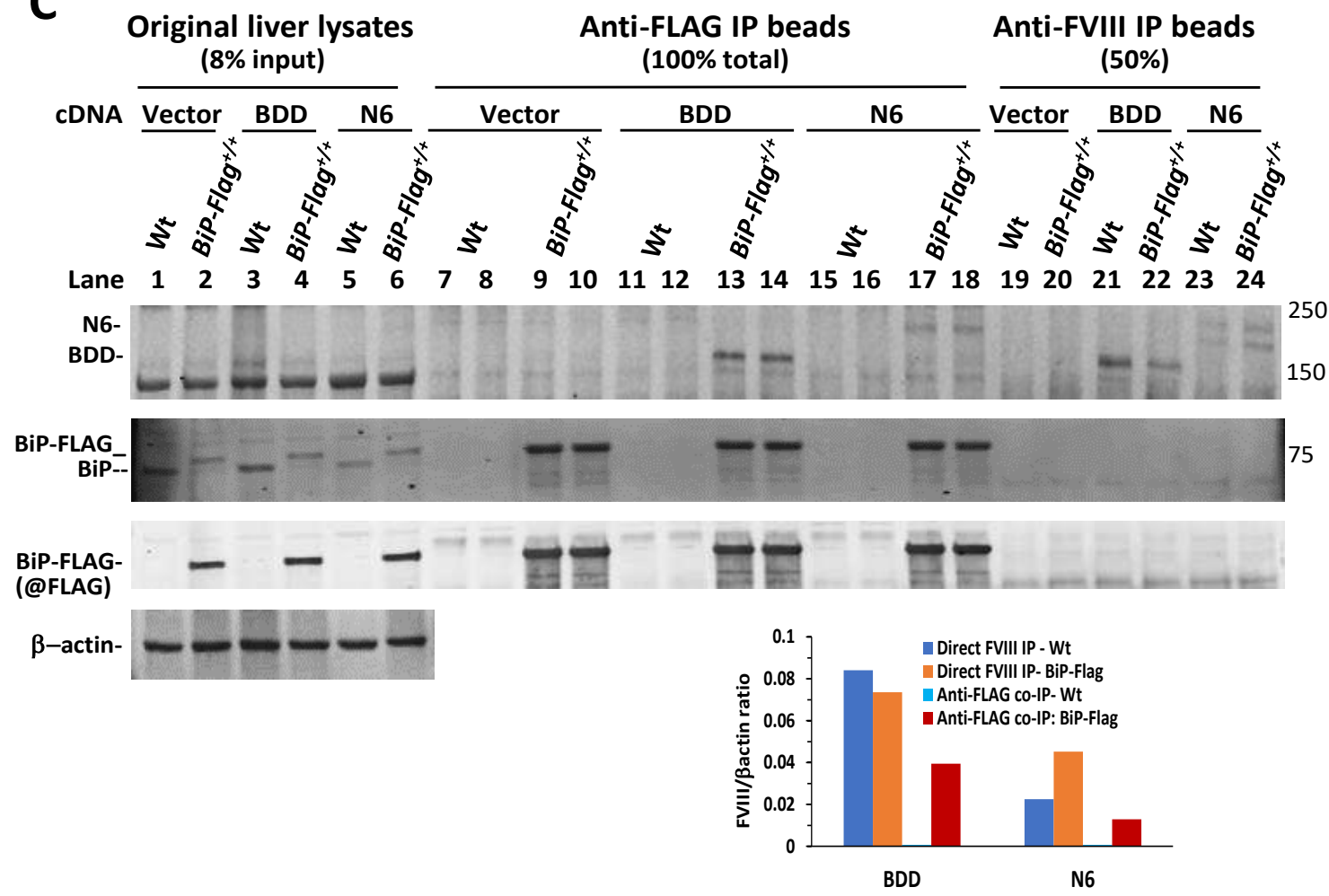

Figure 4. Epitope-tagging of the endogenous murine BIP/GRP78/Hspa5 locus demonstrates misfolding of BDD in vivo. A: A diagram illustrating location of insertion of 3x FLAG tag to C-terminal region of BiP; $\mathrm{B}$ : Western blot demonstrating similar changes in hepatic levels of wild-type $\mathrm{BiP}(\mathrm{BiP})$ and $\mathrm{BiP}-\mathrm{FLAG}$ in mice heterozygous for BiP-Flag allele (10 days after activation of BiP-FLAG expression in the liver) in response to treatment with tunicamycin for $24 \mathrm{~h}$. C. Co-immunoprecipitation (IP) of BDD (lanes 13 \&14) and N6 (lanes 17 \& 18) from liver lysates of BDD or N6 vector-injected BiP-Flag homozygous mice $\left(\right.$ BiP-Flag $\left.^{+/}\right)$with anti-FLAG magnetic beads. Direct FVIII IP using anti-FVIII agarose beads demonstrates the relative levels of BDD and N6 in the liver samples (lanes 21-24). 


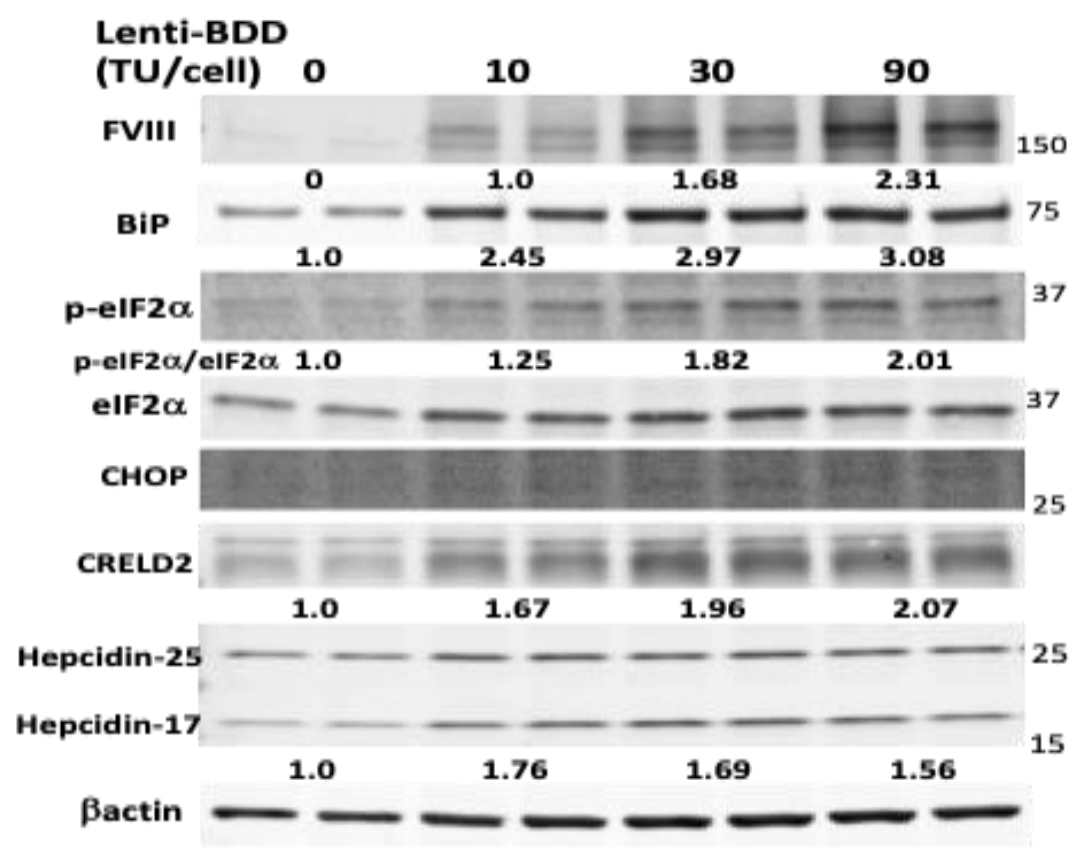

Figure 5. BDD expression induces the UPR in primary human hepatocytes $(\mathrm{PHH})$. $\mathrm{PHH}$ were transduced with a lentiviral vector expressing a codon-optimized form of SQ-BDD (LentiBDD) at the indicated vector doses and cultured in a hepatocyte-defined medium. The transduced $\mathrm{PHH}$ were harvested for western blot analysis 10 days post-transduction. Each lane represents individual culture well. The numerical numbers represent averaged fold changes after correction with loading control $\beta$-actin. 
A

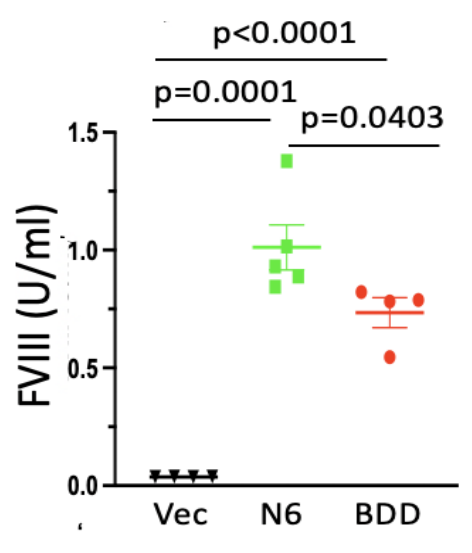

B
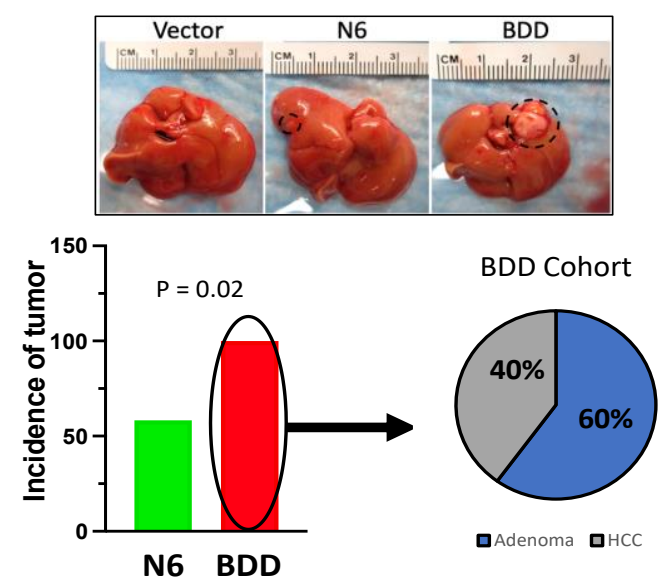

\% Tumors

Vector $0(0 / 13)$

N6 $58(7 / 12)$

BDD $100(10 / 10)$

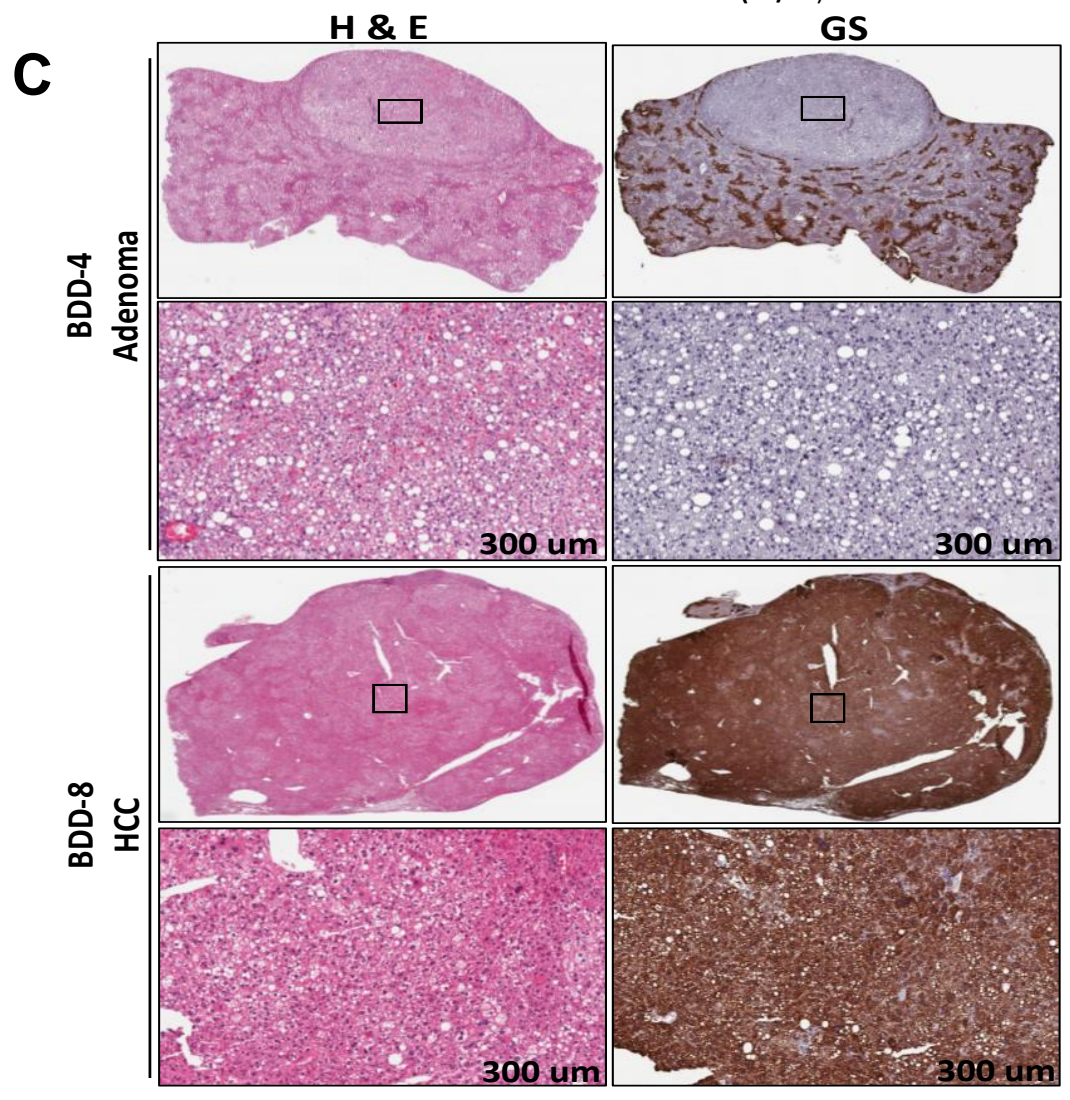

Figure 6. A: Plasma levels of FVIII. WT C57BL/6J mice were injected with pMT empty vector, N6 of BDD vectors by hydrodynamic tail vein injection. After $24 \mathrm{~h}$, plasma was obtained and FVIII levels were measured by ELISA. Data shown are Mean $\pm \mathrm{SE}(\mathrm{N}=4$ for pMT-empty vector and BDD, $\mathrm{N}=5$ for N6) One way ANOVA was used for statistic analysis. B: Incidence of tumors summary and the difference between the two groups (N6 \& BDD) were tested for statistical significance using the Chi-square test (degrees of freedom $=1,95 \%$ confidence intervals). C: Total number of adenoma and HCC incidence (\%) for the BDD cohort. 
A

N6

BDD
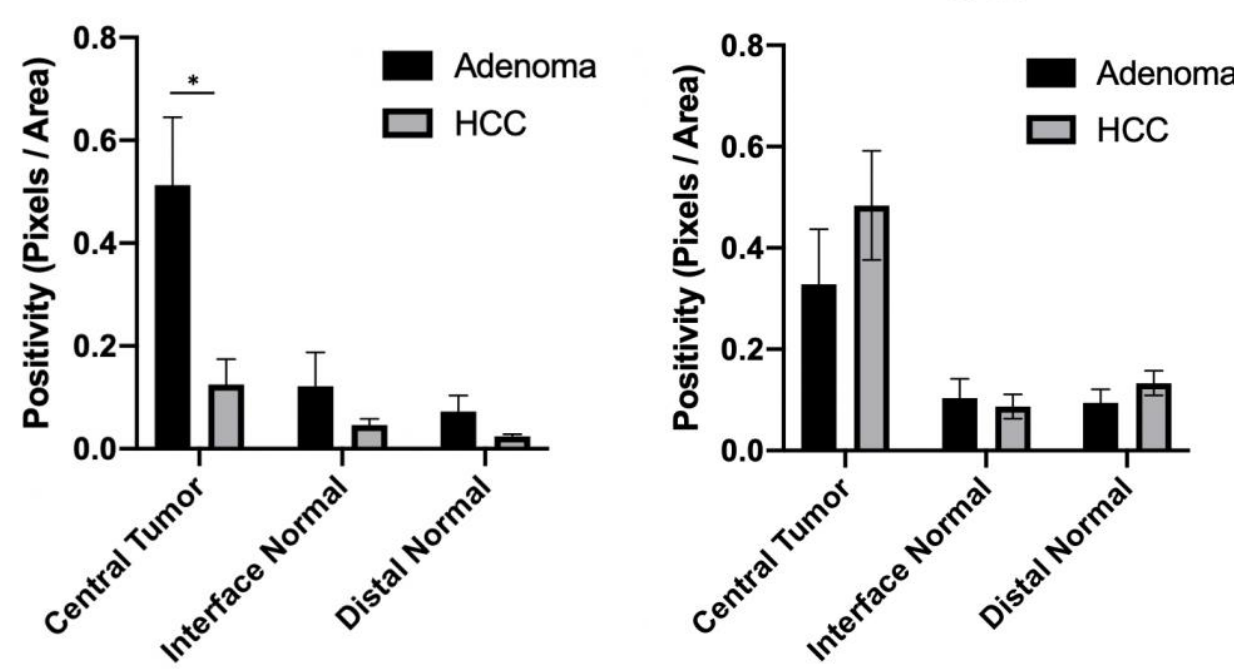

B

Adenoma

\section{HCC}
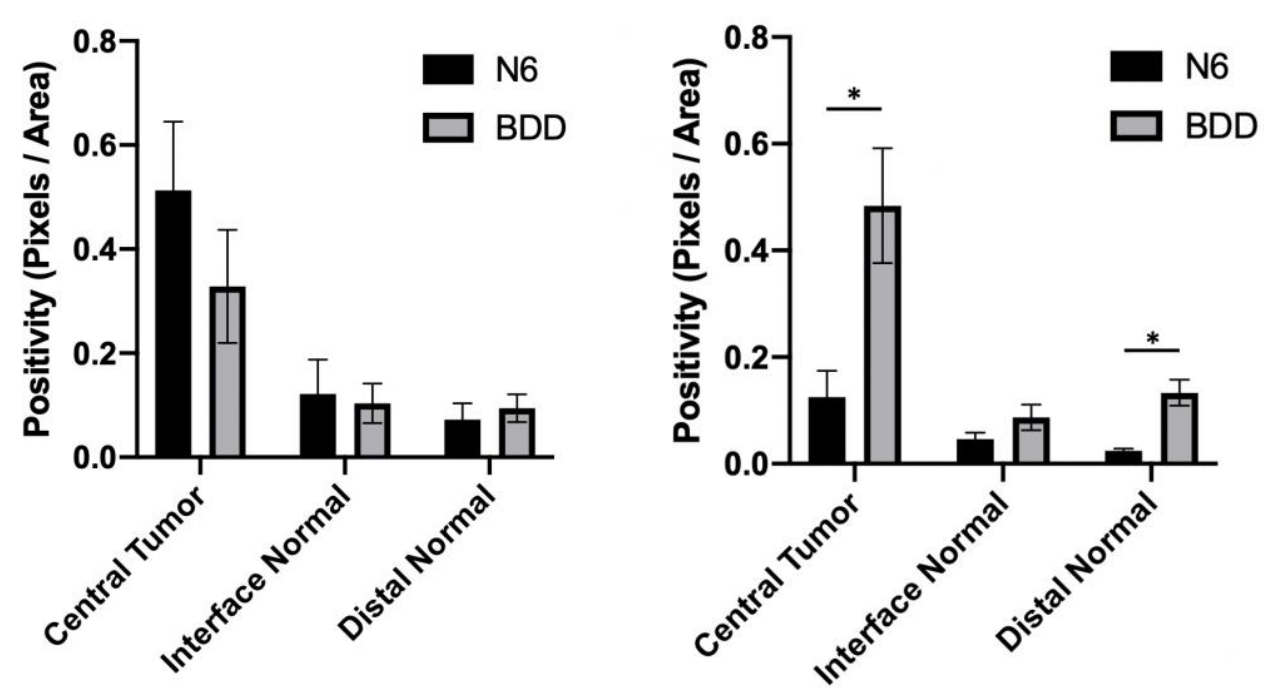

Figure 7. Total Positivity levels (\%) of BiP quantification of FVIII-N6 and FVIIIBDD mouse cohorts. Central tumor, interface normal, and distal normal regions of interest are quantified using the total positive pixel per count algorithm from Aperio software represented as positivity percentage (pixels/Area). A: Comparison of positivity (\%) levels of adenoma and HCC tumor types for N6 and BDD cohorts. B: Comparison of positivity (\%) levels of N6 and BDD cohorts for adenoma and HCC tumor types. Statistical analysis were performed using a two-tailed Student's $t$-test where $P$ values of $<0.05$ were considered to be significant $\left(p<0.05^{*}, p<0.01^{* *}, p<0.001^{* * *}\right)$. 


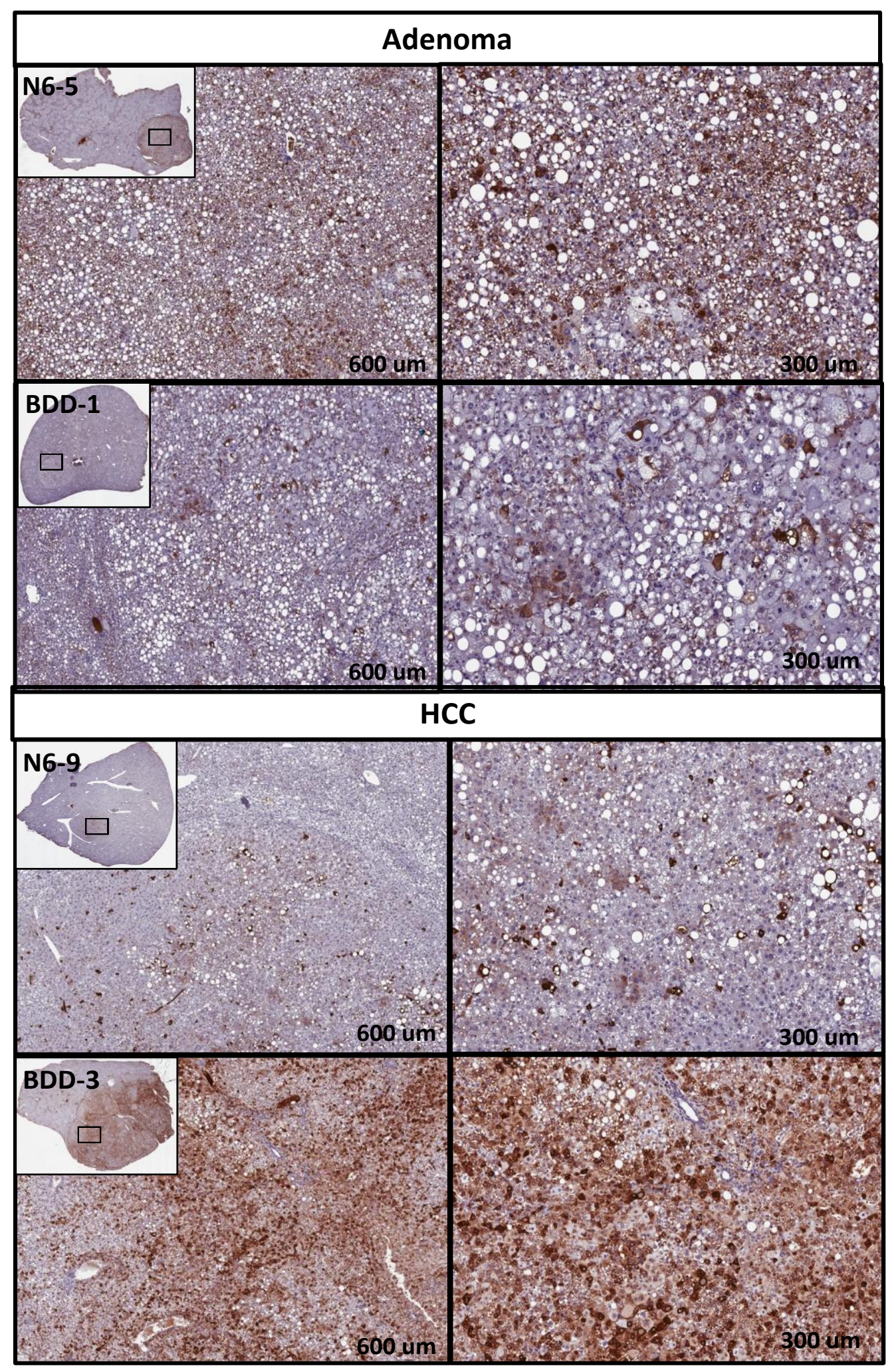

Figure 8. Representation of BiP immunohistochemistry. FVIII-N6 and FVIIIBDD cohort samples (N6-5, N6-9, BDD-1, and BDD-3) for Adenoma and HCC 


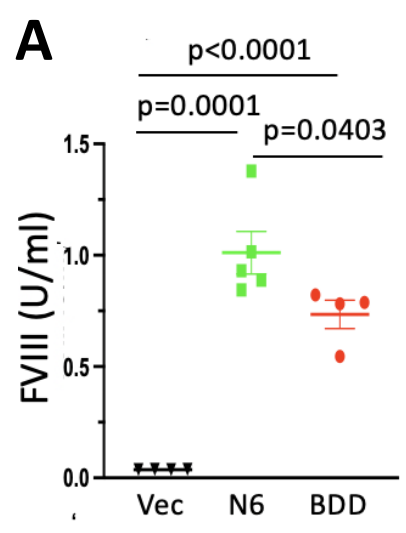

B
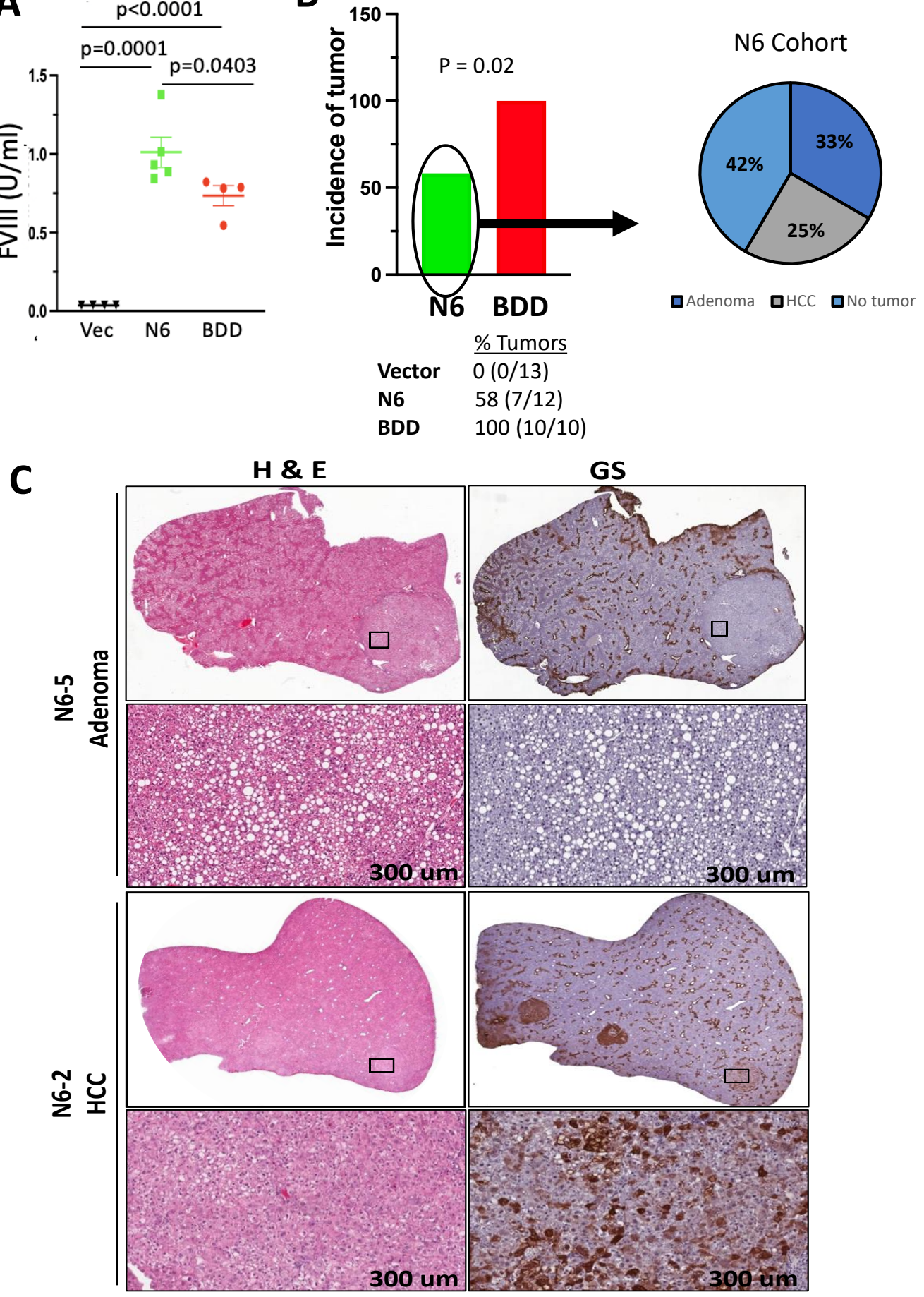

Figure S1. A: Plasma levels of FVIII. WT C57BL/6J mice were injected with pMT empty vector, N6 of BDD vectors by hydrodynamic tail vein injection. After $24 \mathrm{~h}$, plasma was obtained and FVIII levels were measured by ELISA. Data shown are Mean $\pm S E(N=4$ for pMTempty vector and BDD, $\mathrm{N}=5$ for N6) One way ANOVA was used for statistic analysis. B: Incidence of tumors summary and the difference between the two groups (N6 \& BDD) were tested for statistical significance using the Chi-square test (degrees of freedom $=1,95 \%$ confidence intervals). C: Total number of adenoma and HCC incidence (\%) for the N6 cohort. 

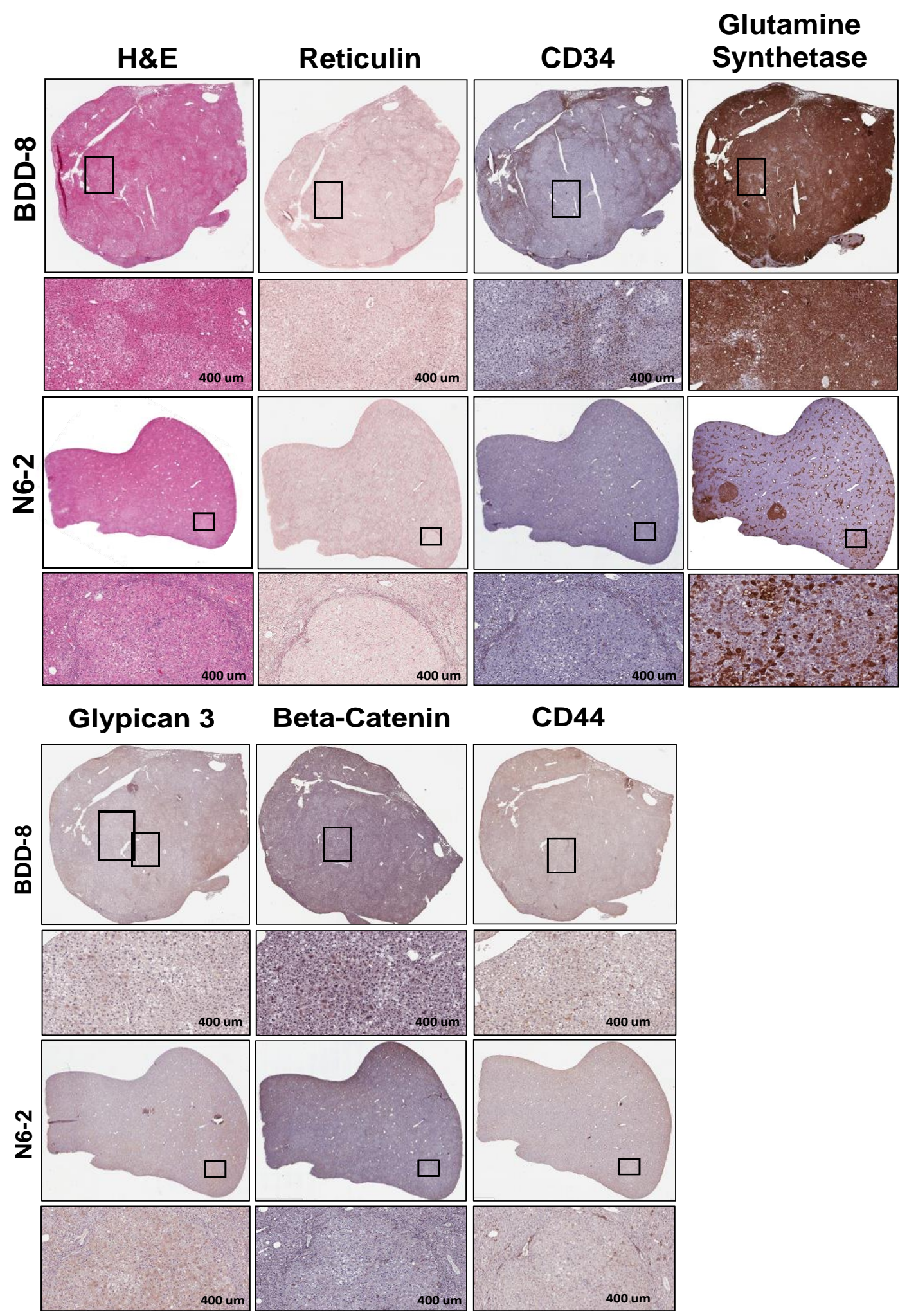

Figure S2. Immunohistochemistry characterization of two (N6-2 and BDD8) HCC samples. Serial sections are stained for H\&E: Hematoxylin and Eosin, reticulin, CD34, glutamine synthetase, glypican-3, Beta-catenin, and CD44. 


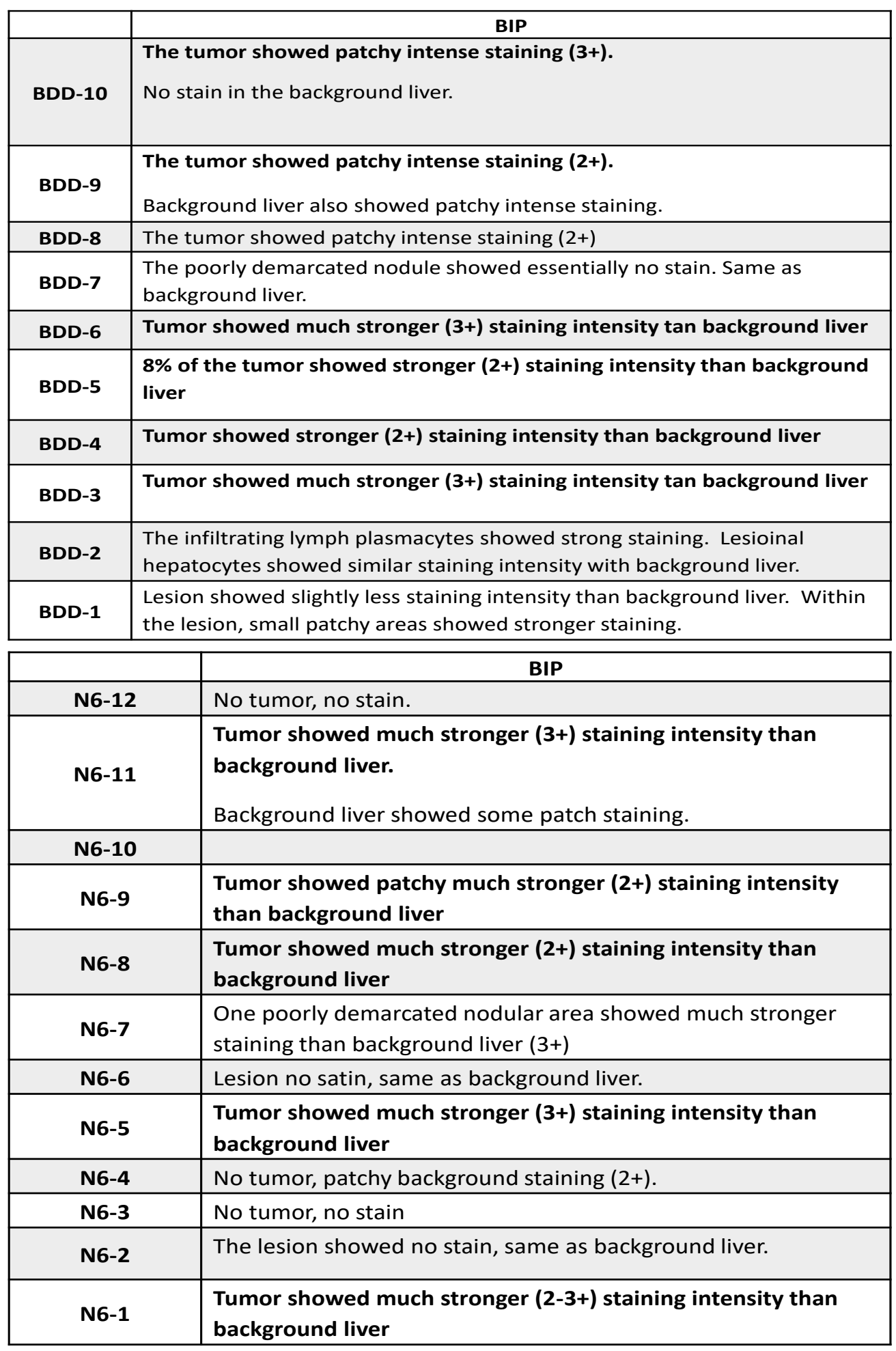

Figure S3. Immunohistochemistry characterization of Bip of two (N6-2 and BDD8) HCC samples. 
bioRxiv preprint doi: https://doi.org/10.1101/2021.01.19.427220; this version posted September 24, 2021. The copyright holder for this preprint (which was not certified by peer review) is the author/funder. All rights reserved. No reuse allowed without permission.

Table S1. Immunohistochemistry characterization of the FVIII-N6 cohort samples.

\begin{tabular}{|c|c|c|c|c|c|c|c|c|}
\hline & H\&E & Glutamine synthetase & CD34 & Reticulin & Beta-catenin & CD44 & Glypican 3 & AFP \\
\hline N6-12 & 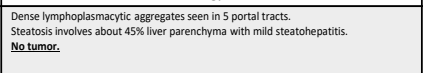 & Normal distribution staining & No tumor & Normal staining pattern & $\begin{array}{l}\text { No lesion. Cytoplasmic } \\
\text { posititity seen in iver cells at } \\
\text { the edge of the tissue (edge } \\
\text { effect) }\end{array}$ & \begin{tabular}{|l|l} 
negative \\
(n)
\end{tabular} & \begin{tabular}{|l|} 
Essentially all negative. \\
At one edge, patch $1 \cdot 2+2$ \\
staining noted.
\end{tabular} & No tumor \\
\hline N6-11 & 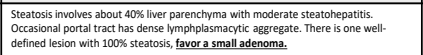 & The nodule showed no staining & 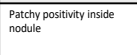 & \begin{tabular}{|l} 
Entirie lesion showed \\
diminished staining
\end{tabular} & \begin{tabular}{|l} 
Lesion negative. Some \\
inflammatory cells positive.
\end{tabular} & \begin{tabular}{|l|l|l} 
Lesion negative \\
\end{tabular} & Lesion negative & $\begin{array}{l}\text { Heavy background, Lesion showed slightly } \\
\text { les staining intensity than background liver. }\end{array}$ \\
\hline N6-10 & 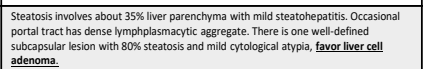 & Tumor mostly positive & Lesion negative & $\begin{array}{l}\text { Lesion cells 1-2 cells thick, } \\
\text { normal reticulin }\end{array}$ & \begin{tabular}{|l|l|} 
Lesion negative \\
\end{tabular} & \begin{tabular}{|l|l|l} 
Lesion negative \\
\end{tabular} & \begin{tabular}{|l|l|} 
Lesion negative \\
\end{tabular} & $\begin{array}{l}\begin{array}{l}\text { Heavy background, Tumor non-steatotic } \\
\text { cells showed similar staining than the } \\
\text { background liver. }\end{array} \\
\end{array}$ \\
\hline N6-9 & 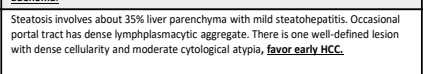 & Tumor diffuse strong staining & \begin{tabular}{|l|l|l} 
Lesion negative \\
\end{tabular} & $\begin{array}{l}\begin{array}{l}\text { Diminished reticulin, thick } \\
\text { trtabeculae, consistent with } \\
\text { HcC }\end{array} \\
\end{array}$ & \begin{tabular}{|l} 
Lesion negative \\
\end{tabular} & \begin{tabular}{|l|} 
Lesion negative \\
\end{tabular} & 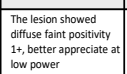 & $\begin{array}{l}\text { Tumor show much stronger staining } \\
\text { intensity than background liver }\end{array}$ \\
\hline N6-8 & 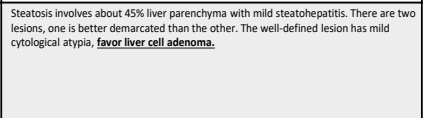 & 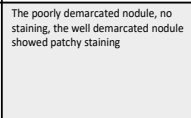 & $\begin{array}{l}\text { The poorly demarcated } \\
\text { nodule, showed some } \\
\text { intralas sional positivity the } \\
\text { weld demarcated ondule is } \\
\text { completely negative }\end{array}$ & $\begin{array}{l}\text { The poorly demaracted nodule } \\
\text { completely lost reticulin, favor } \\
\text { HcC. } \\
\text { The well demarcated nodule } \\
\text { reticulin diminished. }\end{array}$ & 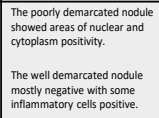 & $\begin{array}{l}\text { Lesion showed focal positivity } \\
\text { 2+, mostly inflammatory cells in } \\
\text { sinusoids are positive. Only a } \\
\text { few hepatocytes positive. }\end{array}$ & \begin{tabular}{|l|}
$\begin{array}{l}\text { The lesion showed } \\
\text { patch focal postivity } \\
1.2+\end{array}$ \\
.
\end{tabular} & $\begin{array}{l}\text { Heavy background. } \\
\text { One lesion showed stronger statining than } \\
\text { background liver. The ether lesion showed } \\
\text { similar staining intensity with hackground } \\
\text { liver. }\end{array}$ \\
\hline N6-7 & $\begin{array}{l}\text { Steatosisi involves about 20\% liver parenchyma with mild steatothepatitis. } \\
\text { No tumor. }\end{array}$ & $\begin{array}{l}\begin{array}{l}\text { Normal distributition staining. At one } \\
\text { edge, a poorly demarcated intensive } \\
\text { staining area noted. }\end{array} \\
\end{array}$ & No tumor. & Normal staining pattern & \begin{tabular}{|l} 
No tumor. A focal positive are \\
likely due to staining artefarct
\end{tabular} & \begin{tabular}{|l|}
$\begin{array}{l}\text { Some sinusoidal lymphocytes } \\
\text { positive, ull hepatoctres } \\
\text { negative }\end{array}$ \\
\end{tabular} & 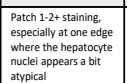 & \begin{tabular}{|l|} 
Heavy background, no tumor \\
\end{tabular} \\
\hline N6-6 & 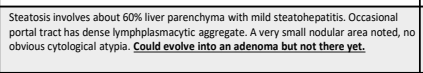 & \begin{tabular}{|l|} 
Normal distribution staining, a small \\
nodular focus showed lack of staining
\end{tabular} & $\begin{array}{l}\text { A small nodular focus, no } \\
\text { stain. }\end{array}$ & $\begin{array}{l}\text { The nodular focus showed } \\
\text { slighty diminishs heticulin, } \\
\text { not obvious }\end{array}$ & \begin{tabular}{|l} 
Lesion negative \\
\end{tabular} & \begin{tabular}{|l} 
In addition to the sinusoidal \\
ymphochtes, the lesional \\
hepatocytes showed faint \\
membranous staining $1+$ \\
\end{tabular} & $\begin{array}{l}\text { Patchy 1-2+2 staining, } \\
\text { especially at the } \\
\text { nodulur focus area. }\end{array}$ & $\begin{array}{l}\begin{array}{l}\text { Lesion non lesion, no difference. Heavy } \\
\text { background }\end{array} \\
\end{array}$ \\
\hline N6-5 & 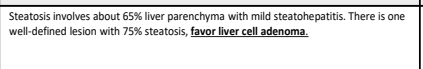 & \begin{tabular}{|l|} 
Lesion negative \\
\end{tabular} & Lesion negative & \begin{tabular}{|l|l} 
Reticulin loss in the lesion area \\
\end{tabular} & 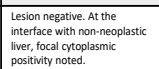 & \begin{tabular}{|l|l|l} 
Lesion negative \\
\end{tabular} & \begin{tabular}{|l|}
$\begin{array}{l}\text { Very small focal areas } \\
\text { in the lesion positive } 1 \text { (1- } \\
\text { 2+1). Mostly the lesion } \\
\text { negative }\end{array}$ \\
\end{tabular} & $\begin{array}{l}\text { Shattered, heavy background. Lesional area } \\
\text { looks paler. }\end{array}$ \\
\hline N6-4 & $\begin{array}{l}\text { Steatosisi involves about } 85 \% \text { \% liver parenchyma with mild steatohepatitis. There is a } 0.07 \\
\text { cmarea with cell ballo oning and start forming a nodular appearance. No definitive } \\
\text { tumor. }\end{array}$ & \begin{tabular}{|l|} 
Normal distribution staining \\
\end{tabular} & \begin{tabular}{|l|l} 
Negative \\
\end{tabular} & Normal reticulin network & $\begin{array}{l}\text { No lesion, staining quality not } \\
\text { goodd crtoplasmis staining see } \\
\text { in patchy areas, probably not } \\
\text { real. }\end{array}$ & \begin{tabular}{|l|l|l} 
All negative \\
\end{tabular} & \begin{tabular}{|l}
$\begin{array}{l}\text { Focal and patchy } 2+ \\
\text { staining noted. }\end{array}$ \\
\end{tabular} & \begin{tabular}{|l} 
No tumor, heavy background. \\
\end{tabular} \\
\hline N6-3 & Steatosisis involves about 65\% liver parenchyma with mild steatohepatitis. No tumor. & Normal distribution staining & 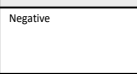 & Normal reticulin network & $\begin{array}{l}\begin{array}{l}\text { No lesion. Cytoplasmic } \\
\text { posititity yeen in iver cells at } \\
\text { the edge of he tisue (edge } \\
\text { effect) }\end{array} \\
\end{array}$ & \begin{tabular}{|l} 
All negative \\
\end{tabular} & \begin{tabular}{|l|l} 
No tumor, all negative \\
\end{tabular} & No tumor, some background staining \\
\hline N6-2 & 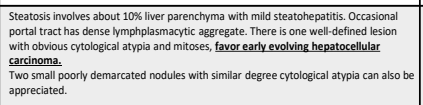 & Showed 3 nodules, all positive & \begin{tabular}{|l|} 
Lesions all Negative. \\
Only one nodule obvious
\end{tabular} & $\begin{array}{l}\text { Reticulin loss in noe nodule. } \\
\text { Diminished reticulin in two } \\
\text { other nodules. }\end{array}$ & \begin{tabular}{|l|}
2 small lesions negative. \\
1 larger lesion showed focal \\
patchy cytoplasmic positivity
\end{tabular} & $\begin{array}{l}\text { one small lesion negative. } \\
\text { The larger well recognized } \\
\text { lesion and one small lesion } \\
\text { showed } 1+\text { membranous } \\
\text { staining on hepatocytes }\end{array}$ & \begin{tabular}{|l|}
2 small lesions \\
negative. \\
The larger well \\
recognized lesion \\
positive $(1-2+)$
\end{tabular} & $\begin{array}{l}\text { One poor demarcated nodule showed } \\
\text { stronger staining than the background liver }\end{array}$ \\
\hline N6-1 & 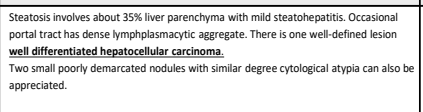 & Tumor diffusely positive & $\begin{array}{l}\text { Strong positivity inside the } \\
\text { tumor in tow lesions. trit } \\
\text { one no stain (unable to } \\
\text { recognize the nodule) }\end{array}$ & $\begin{array}{l}\text { The large nodule showed areas } \\
\text { lost reticulin. } \\
\text { Favor malignant. }\end{array}$ & \begin{tabular}{|l}
$\begin{array}{l}\text { Lesion strong crtoplasmic } \\
\text { positivity, patchy but real }\end{array}$ \\
\end{tabular} & $\begin{array}{l}\text { Tumor negative. } \\
\text { The dense Iymphoid aggregate } \\
\text { between two vessel showed } 3+ \\
\text { staining. }\end{array}$ & $\begin{array}{l}\text { Entire lesion faint } \\
\text { positive 1+. } \\
\text { Non-neoplastic liver } \\
\text { showed patchy } \\
\text { positivity (2+). }\end{array}$ & $\begin{array}{l}\text { Heavy background. Tumor showed patch } \\
\text { strong positivity. }\end{array}$ \\
\hline
\end{tabular}


bioRxiv preprint doi: https://doi.org/10.1101/2021.01.19.427220; this version posted September 24, 2021. The copyright holder for this preprint (which was not certified by peer review) is the author/funder. All rights reserved. No reuse allowed without permission.

Table S2. Immunohistochemistry characterization of the FVIII-BDD cohort samples.

\begin{tabular}{|c|c|c|c|c|c|c|c|c|}
\hline & H\&E & Glutamine synthetase & CD34 & Reticulin & B-catenin & CD44 & Glypican 3 & AFP \\
\hline BDD-10 & 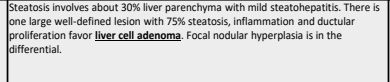 & Tumor completely negative & \begin{tabular}{|l|l}
$\begin{array}{l}\text { Patchy strong positive in the } \\
\text { center of the lesion }\end{array}$ \\
\end{tabular} & \begin{tabular}{|l}
$\begin{array}{l}\text { Patchy loss of reticulin } \\
\text { network. }\end{array}$ \\
\end{tabular} & 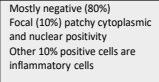 & 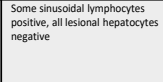 & \begin{tabular}{|l|l} 
Lesion negative. \\
\end{tabular} & 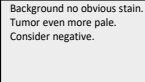 \\
\hline BDD-9 & 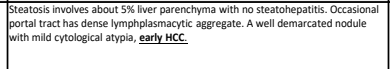 & \begin{tabular}{|l}
$\begin{array}{l}\text { The tumor stained completely postive, } \\
\text { may indicate malignant }\end{array}$ \\
\end{tabular} & \begin{tabular}{|l|l|l} 
Lesion negative \\
\end{tabular} & \begin{tabular}{|l}
$\begin{array}{l}\text { Tumor nearly completely loss } \\
\text { of ferticulin etwork, favor } \\
\text { malignant }\end{array}$ \\
\end{tabular} & \begin{tabular}{|l|l} 
Lesion negative \\
\end{tabular} & \begin{tabular}{|l|l} 
Lesion negative \\
\end{tabular} & 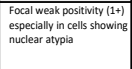 & \begin{tabular}{|l|} 
Heavy background, Tumor \\
non-steatotic cells showed \\
strongeg staining than the \\
background liver.
\end{tabular} \\
\hline BDD-8 & $\begin{array}{l}\text { Steatosis involves about } 5 \% \text { IVer parenchyma with no steatohe pattits. A tumor } \\
\text { lesion with poorly defined borders and cytologogical atypia, could be an early HCC. }\end{array}$ & \begin{tabular}{|l|} 
Entire silde stained positive, patchy pale \\
focus, may indicate maligant
\end{tabular} & \begin{tabular}{|l|} 
Lesion mostly negative, at one \\
end, Patchy strong postivity
\end{tabular} & \begin{tabular}{|l} 
Reticulin is lost in 80\% of the \\
lesion
\end{tabular} & \begin{tabular}{|l|l|} 
Nuclear positivity presents \\
\end{tabular} & \begin{tabular}{|l|l|l} 
Lesion negative \\
\end{tabular} & $\begin{array}{l}\text { Lesion showed patchy } \\
\text { postivity 1+. }\end{array}$ & \begin{tabular}{|l}
$\begin{array}{l}\text { Heawy background, tumor } \\
\text { showed patchy strong } \\
\text { positvitit. }\end{array}$ \\
\end{tabular} \\
\hline BDD-7 & 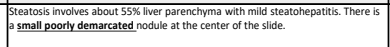 & \begin{tabular}{|l|}
$\begin{array}{l}\text { Very small poorly developed lesion area, } \\
\text { stained negative }\end{array}$ \\
\end{tabular} & $\begin{array}{l}\text { Lesional areace positive, } \\
\text { periphery, extend to the } \\
\text { centrer }\end{array}$ & \begin{tabular}{|l|} 
Lesional area showed \\
diminished reticulin and focal \\
loss.
\end{tabular} & \begin{tabular}{|l|l|} 
Lesion negative \\
\end{tabular} & \begin{tabular}{|l|l|} 
Some sinusoidal lymphocottes \\
positive, all esional and non- \\
lesional hepatocytes negative
\end{tabular} & \begin{tabular}{|l}
$\begin{array}{l}\text { Lesion completely } \\
\text { negative }\end{array}$ \\
\end{tabular} & \begin{tabular}{|l} 
Heary background. The poorly \\
demaracten nodule showed \\
essentially no ostain.
\end{tabular} \\
\hline BDD-6 & 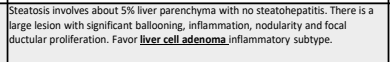 & \begin{tabular}{|l|} 
Lesion negative \\
Favor adenoma, ruled out FNH
\end{tabular} & \begin{tabular}{|l|} 
Overall, the lesion is negative \\
\end{tabular} & \begin{tabular}{|l|}
$\begin{array}{l}\text { Lesion showed diminished } \\
\text { reticulin and focal loss. }\end{array}$ \\
\end{tabular} & \begin{tabular}{|l|l} 
Lesion negative \\
\end{tabular} & 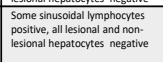 & \begin{tabular}{|l|}
$\begin{array}{l}\text { Lesion completely } \\
\text { negative }\end{array}$ \\
\end{tabular} & 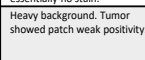 \\
\hline BDD-5 & 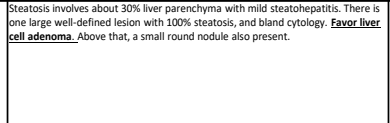 & \begin{tabular}{|l|}
$\begin{array}{l}\text { Upper small nodule negative. } \\
\text { Lesion middle area neagtive } \\
\text { Lesion lower area parchy positive normal } \\
\text { liver pattern. }\end{array}$
\end{tabular} & 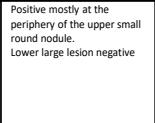 & 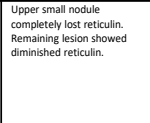 & \begin{tabular}{|l} 
Lesion negative \\
\end{tabular} & \begin{tabular}{|l|} 
Upper small nodule negative. \\
The larger nodule showed focal \\
hepatocote 1 + membranous \\
positivity.
\end{tabular} & 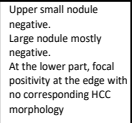 & \begin{tabular}{|l|} 
Heavy background, Tumor \\
showeded less staining due to \\
steatosis. Non steatotic area \\
of the tumor shhow simliar \\
staining intensity with the \\
background liver.
\end{tabular} \\
\hline BDD-4 & 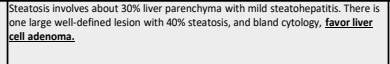 & Lesion negative & \begin{tabular}{|l|l} 
Lesion negative \\
\end{tabular} & 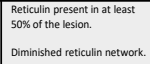 & \begin{tabular}{|l} 
Lesion negative \\
\end{tabular} & \begin{tabular}{|l|l} 
Lesion negative \\
\end{tabular} & \begin{tabular}{|l|l} 
Lesion negative \\
\end{tabular} & $\begin{array}{l}\begin{array}{l}\text { Heavy background, tumor } \\
\text { essentially negative }\end{array} \\
\end{array}$ \\
\hline BDD-3 & 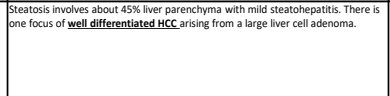 & \begin{tabular}{|l|l} 
Lesion negative \\
\end{tabular} & \begin{tabular}{|l} 
With the nodule, a strong \\
positive area "nodule in \\
nodulel support thc arising \\
from an adenoma
\end{tabular} & $\begin{array}{l}\text { Approximateley } 65 \% \text { of lesion } \\
\text { showed loss of reteciclin } \\
\text { Diminished reticulin network. } \\
\text { The area ith no reticilin } \\
\text { correspond to the malignant } \\
\text { looking area in } \mathrm{HE}\end{array}$ & 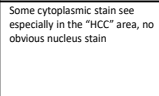 & 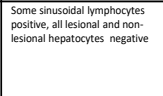 & \begin{tabular}{|l|l} 
Lesion negative \\
\end{tabular} & $\begin{array}{l}\text { Heavy background. Tumor } \\
\text { overall less staining than the } \\
\text { background liver, patch weak } \\
\text { stains. }\end{array}$ \\
\hline BDD-2 & 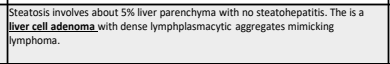 & \begin{tabular}{|l|l} 
Lesion negative, normal liver distribution \\
\end{tabular} & Lesion negative & 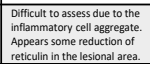 & \begin{tabular}{|l|l|l} 
Lesion negative \\
\end{tabular} & \begin{tabular}{|l|} 
Dense lymphoid agregeates \\
positive, all lesional and non \\
lesional hepatocytes negative
\end{tabular} & Lesion negative & 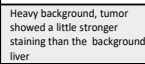 \\
\hline BDD-1 & $\begin{array}{l}\text { Steatosis involves about } 40 \% \text { liver parenchyma with minimum steatohepatitis. } \\
\text { There is a well demarcated lesion with hland cytology favor liver cell adenom. }\end{array}$ & \begin{tabular}{|l|l} 
Lesion negative \\
\end{tabular} & \begin{tabular}{|l|l|l} 
Lesion negative \\
\end{tabular} & 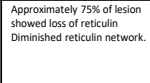 & \begin{tabular}{|l} 
Lesion negative \\
\end{tabular} & 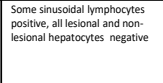 & \begin{tabular}{|l|l} 
Lesion negative \\
\end{tabular} & 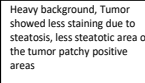 \\
\hline
\end{tabular}

